\title{
LA SITUACIÓN LABORAL DE LOS ADULTOS MAYORES EN HONDURAS
}

Norma Adriana Castillo Bertrand, Universidad Nacional Autónoma de Honduras (UNAH), Facultad de Ciencias Económicas (FCE), Instituto de Investigaciones Económicas y Sociales (IIES), Ciudad universitaria, edificio C2, primer piso, Tel/fax: (504) 2239-1849

\section{RESUMEN}

E-mail: ncastillo@iies-unah.org

En América Latina y el Caribe, se está produciendo un inexorable envejecimiento de la población, y constituye un proceso generalizado, pues todos los países de la región se van convirtiendo a un ritmo distinto, en sociedades más envejecidas.

De esta manera se percibe como en los distintos países de la región se encuentran en distintas etapas de la transición demográfica descrita por los niveles que presentan las variables de fecundidad y mortalidad en el quinquenio de 2010-2015 (CEPAL/CELADE, 2008).

De forma particular, Honduras según los datos facilitados por CEPAL en el 2008, se ubica en la fase de plena transición porque los valores de la Tasa Global de Fecundidad (TGF) es de 3 hijos por mujer y la Esperanza de Vida al nacer de 73.6 años los cuales están cercanos al promedio regional (2.16 hijos por mujer y 74.7años) respectivamente.

Según los datos de la Encuesta Permanente de Hogares y Propósitos Múltiples (EPHPM) Mayo 2012, la población total de adultos mayores asciende a 786,016 lo que representa el $8.6 \%$ de la población total. Por otro lado, al revisar la Población Económicamente Activa (PEA) de este grupo etario, se calculó en aproximadamente 331,688 personas donde el $99.5 \%$ están ocupados y el $0.5 \%$ desocupados. De los ocupados, el $67.5 \%$ son hombres y el $32.5 \%$ son mujeres participando en mayores porcentajes los comprendidos en las edades de 60-69 años.

Palabras clave: Población adulta mayor, mercado laboral, condición de ocupación. 


\title{
THE ELDERLY LABORAL CONDITIONS ON THE HONDURAN CONTEXT
}

Vol. 4

E\&A

IIES

\begin{abstract}
Norma Adriana Castillo Bertrand, Universidad Nacional Autónoma de Honduras (UNAH), Facultad de Ciencias Económicas (FCE), Instituto de Investigaciones Económicas y Sociales (IIES), Ciudad universitaria, edificio C2, primer piso, Tel/fax: (504) 2239-1849

E-mail: ncastillo@iies-unah.org
\end{abstract}

\begin{abstract}
In Latin America and the Caribbean, an inexorable aging phenomenon is affecting the population and is in a generalized process, spreading through all the countries in the region, at different paces.
\end{abstract}

Nonetheless, one can perceive how in the various these demographic transitions along the different countries in the region are evolving to dissimilar stages of fertility and mortality in the periods of 2010-2015 (ECLAC / CELADE, 2008).

Honduras based on these data, it is located in the middle of a transition phase because the values of the total fertility rate (TFR) is 3 children per woman and life expectancy at birth of 73.6 years which are close to the regional average ( 2.16 children per woman and 74.7años ) respectively.

According to the Household Survey and General Purposes (PMHS) May 2012, the total elderly population condenses a total of 786.016 which represents $8.6 \%$ of the total population. On the other hand, the economically active population (EAP) of this age group is approximately 321.669 people where $99.5 \%$ are employed and $0.5 \%$ are unemployed. Among the occupied population segment $67.5 \%$ are men and $32.5 \%$ women participating in higher percentages, within the ages of 60-69 years.

Keywords: Elder Population, Laboral Force, Occupational Condition. 


\section{INTRODUCCIÓN}

El envejecimiento de la población está tomando notoriedad en los últimos años dado que la población mundial está envejeciendo a pasos acelerados, donde la proporción de la población mayor de 60 años se duplicara en el periodo de 20002050 pasando de $11 \%$ a $22 \%$.

Así, en la Segunda Conferencia Mundial sobre el envejecimiento 2002, los países participantes en la misma se comprometieron mediante dos documentos (Plan de Acción Internacional y la Declaración Política) a diseñar y ejecutar medidas para enfrentar los retos que plantea el envejecimiento. (CEPAL. 2002). Aunque el problema del envejecimiento preocupa cada vez más a muchos países industrializados y en vías de desarrollo, durante las últimas décadas se le ha prestado atención a los aspectos políticos, económicos y sociales inherentes a la "tercera edad", tanto los que afectan al individuo (desde el punto de vista humanitario) como aquellos vinculados al fenómeno del envejecimiento absoluto y relativo de la población, y sus implicaciones socioeconómicas (Frómeta Sánchez, E. y Estrada, R. P. 1997). Además Villa y Rivadeneira apuntan que las personas envejecen a medida que trascurre su ciclo de vida, pero las poblaciones envejecen cada vez que las cohortes de edades aumentan su ponderación dentro de su conjunto.

El envejecimiento es un fenómeno demográfico fruto de la transición demográfica, que se caracteriza por una continua reducción en las tasas de fecundidad y de mortalidad, la última descendió antes que la primera, por lo que durante el periodo de transición la tasa de crecimiento es alta y la población aumenta.

El declive de la tasa de mortalidad en Honduras se da a mediados del siglo XX, en la década de los años cincuenta con la importación a bajo costo de medicamentos descubiertos en los países desarrollados, mejor acceso a los servicios de salud, ampliación en la cobertura educativa y el mejoramiento del saneamiento ambiental (Flores Fonseca, M. 2007).

La disminución de la mortalidad a lo largo de estas décadas ha provocado que la esperanza de vida al nacer aumente. En Honduras entre 1950- 2010, la esperanza de vida ha aumentado de 41.8 años hasta llegar a los 73.1 años. Este indicador ha provocado un crecimiento paulatino de la población adulta mayor en Honduras, pero en los últimos años se ha acelerado. 
Vol. 4

E\&A

IIES

Por otra parte según datos del Instituto Nacional de Estadística (INE) para mayo 2012, el país contaba con 786,018 adultos mayores, representando el 9.4\% de la población total.

En el contexto del país, la población adulta mayor se localiza en una situación de vulnerabilidad, porque aproximadamente solo el $10 \%$ de este grupo etario de la población tienen acceso a los sistemas de jubilación lo que repercute en su calidad de vida.

Este estudio pretende conocer y analizar las características económicas de este grupo poblacional para el año 2012, a fin de romper con el paradigma que las personas en esta etapa de su vida no tienen nada que aportar a la sociedad, que son dependientes de sus familias y que no contribuyen a la economía familiar ni a la actividad económica del país. Ante lo apuntado anteriormente el estudio revela como en la actualidad, existen personas que todavía participan de la actividad económica en esta etapa de su vida. Igualmente se aspira a que este estudio genere inquietudes y despierte el interés de los tomadores de decisiones, sobre todo porque el indicador de la relación de dependencia aumenta a pasos acelerados. Esta relación da una idea de la carga económica promedio que cada trabajador activo tendrá para mantener a las personas "teóricamente" inactivas.

\section{OBJETIVOS}

\subsection{Objetivo General}

Analizar la participación de los adultos mayores hondureños en el mercado laboral.

\subsection{Objetivos Específicos}

1. Conocer las características sociodemográficas de los adultos mayores que participan en el mercado laboral de Honduras.

2. Conocer las principales características económicas de los adultos mayores. 


\section{MARCO DE REFERENCIA}

\subsection{Conceptualización de Adulto Mayor}

El ser humano es un ser envejeciente, como parte de un proceso físico; el envejecimiento se puede definir a través de varios enfoques, entre ellos se encuentra el biológico, medico, científico, geriátrico, psicológico etc. Todas las definiciones de los enfoques mencionados anteriormente, se concentran en dos tipos de envejecimiento: lo individual y lo poblacional.

A nivel individual, es el proceso de evolución hasta ahora irreversible que cada persona experimenta en su ciclo de vida. Este ciclo está relacionado con dos grandes dimensiones la edad y la estructura del sistema social. En cuanto la edad es entendida como la gran variable que nos ayuda a comprender la vejez; en cambio la estructura del sistema social, está referida a la sociedad y sus reglas; las cuales imponen pautas de comportamiento y de conducta. (Aranibar, P. 2001).

La edad, como se afirma anteriormente es la gran variable para definir envejecimiento o adulto mayor, en muchos países consideran un adulto mayor a las personas de 65 años y más; en otros a las personas de 60 años y más. Las Naciones Unidas definen adultos mayores a las personas de 65 años y más para los países desarrollados y a las personas de 60 años y más para los países en desarrollo.

La Organización Mundial de la Salud divide a los adultos mayores en tres subgrupos: de 60 a 74 años, se consideran personas de edad avanzada, de 75 a 90 años ancianas o viejas, y las que sobrepasan los 90 años, se les llama grandes viejos o grandes longevos.

Según Popolo del Fabiana, 2000. El término "envejecimiento", se asocia comúnmente al proceso biológico que experimenta una persona cuando va ganando años. Sin embargo, el comienzo y la percepción de la vejez tienen que ver no sólo con la evolución cronológica sino también con fenómenos de naturaleza biopsíquica y social.

A nivel poblacional o demográfico, el envejecimiento es un proceso mediante en el cual se producen transformaciones en la composición por edad y sexo de una población (lo que también se llama estructura por edad, representada gráficamente por la pirámide de edades.) o como lo señalara Chesnais; es el aumento de la 
Vol. 4

E\&A

IIES

proporción de personas de edad avanzada con respecto a la población total; lo cual produce una inversión en la pirámide de edades (Chesnais, 1990).

Para las Naciones Unidas el envejecimiento de la población es un proceso gradual donde la proporción de los adultos y ancianos aumenta en una población, mientras disminuye la proporción de niños y adolescentes, ocasionando un aumento en la edad mediana de la población. Asimismo, el envejecimiento ocurre cuando descienden las tasas de fecundidad en tanto permanece constante o mejora la esperanza de vida a edades más avanzadas.

(http://ccp.ucr.ac.cr/cursos/demografia03/glosario.html).

Asimismo es el resultado de las tres principales variables de la demografía (a) una sostenida caída en la tasa de fecundidad, (b) la reducción de la mortalidad durante la segunda mitad de la vida y (c) las migraciones que expulsan jóvenes de determinadas regiones. Sin embargo, en el largo plazo el envejecimiento de la población, reconoce como causa fundamental la sostenida declinación de la fecundidad(INDEC, 1999)

\subsection{EI Proceso de Envejecimiento de la Población en América Latina}

De acuerdo al profesor Jean Claude Chesnais, el proceso de envejecimiento de la región aparece como un fenómeno vinculado, por un lado, al aumento del número absoluto de personas en ese grupo etario y, por otro, al claro mejoramiento de la calidad de vida en los años de sobrevida.

Los antecedentes históricos señalan a Uruguay como el país que inició un acelerado descenso de la fecundidad a principios del siglo XX, hasta la década de 1950, seguido por Argentina 25 años más tarde.

El proceso de envejecimiento en América Latina en las últimas décadas se ha visto caracterizado por tres aspectos:

1. Es un proceso generalizado, porque en todos los países del área, la población mayor de 60 años está aumentando, tanto en términos absolutos como relativos. La proporción de adultos mayores pasará de un $8 \%$ en el año 2000 a $14.1 \%$ en 2025 .

2. El ritmo del envejecimiento en la región es más rápido de lo que fue 
históricamente en los países desarrollados como por ejemplo en Europa.

3. Este proceso es un fenómeno que día a día toma mayor importancia en la región, por la heterogeneidad entre los países de la región.

El Centro Latinoamericano de Demografía (CELADE) elaboró una tipología para identificar el proceso de envejecimiento en que se encuentran los países de la región:

a. Envejecimiento Incipiente: Comprende a los países donde el porcentaje de las personas de 60 años y más oscilan entre el 5\% y el 7\%. Esto incluye a países como Bolivia, Guatemala, Haití, Nicaragua y Paraguay.

b. Envejecimiento Moderado: Comprende a los países donde el porcentaje de las personas de 60 años y más oscilan entre el 6\% a 8\%. En este grupo se sitúan Belice, Colombia, Costa Rica, Ecuador, El Salvador, Guyana, México, Perú, República Dominicana, Venezuela y Honduras.

c. Envejecimiento moderado avanzado: Se caracteriza porque en la actualidad los porcentajes de personas de 60 años y más esta entre $8 \%$ y 10\%. Entre estos países están Bahamas, Brasil, Chile, Jamaica, Suriname y Trinidad y Tobago.

d. Envejecimiento avanzado: Se sitúan aquellos países donde el porcentaje de las personas de 60 años y más oscila entre un 25 - 30\%. Entre esos países se encuentran países como Argentina y Uruguay, pioneros en el envejecimiento en América Latina, más Cuba y México. Así como varios países del Caribe (Antillas Neerlandesas, Barbados, Guadalupe, Martinica y Puerto Rico. (CEPAL, 2004)

El proceso de envejecimiento de la región es un efecto de la disminución en la tasa de fecundidad así como por el descenso en la tasa de mortalidad. De acuerdo a estimaciones de Naciones Unidas (2005), CELADE (2010 rev 2012) plantean que la disminución de la fecundidad se viene presentando desde los años setenta cuando cayó fuertemente; en cambio el descenso de la mortalidad, se dio a inicios de la primera mitad del siglo XX. Por esa razón las personas de 60 años y más en 1950, apenas alcanzaba los 9.4 millones. En 1975, la disminución de la mortalidad comienza a hacerse visible en América Latina al bajar el ritmo de crecimiento de la población y producirse un aumento en la población mayor la cual llegó a alcanzar los 20 millones de personas; en el 2000, ascendió a 43 millones y actualmente (2012), dicha población casi alcanza los 59 millones. Se estima que para 2025, esa cifra se duplicará llegando a alcanzar los 100 millones y para la segunda mitad del siglo XXI podría llegar a 183.7 millones. 
Vol. 4

E\&A

IIES

El peso de los adultos mayores en la población total de América Latina pasará de 8.1\% en el 2000 a $14.5 \%$ en el 2025 y en el 2050 llegará al 24.1\%(CELADE, 2006)

El rápido envejecimiento de la población ha dado pie para que los países se reúnan a discutir el tema. Una de esas reuniones fue la Segunda Asamblea Mundial sobre el Envejecimiento celebrada en Madrid en el año 2002, donde se aprobó el Plan de Acción Internacional sobre el Envejecimiento, el cual contiene tres áreas que son prioridad:

a. Seguridad Económica, vista desde la capacidad de las personas mayores de disponer de bienes de general, económicos y no económicos dado que es un elemento clave en la calidad de vida en la vejez.

b. Salud, porque las cohortes que alcanzaron los 60 años y más después de los años noventa, son producto de los beneficios médico-sanitarios durante el período posterior a la segunda guerra mundial. Estos beneficios contribuyeron a la disminución de la mortalidad, al aumento en la esperanza de vida y a la mejora de la salud de las personas. No obstante, persisten desigualdades en las condiciones de salud y de acceso de atención de las personas mayores.

c. Entornos Favorables, con este elemento se prevé la creación de condiciones esenciales, tales como la eliminación de la violencia y la discriminación así como el fomento de condiciones materiales que ayuden a la vida en comunidad de estas personas.

\subsection{Población Económicamente Activa de los Adultos Mayores en América Latina}

En últimos años, los países de la región han tenido un importante avance en la transición demográfica, lo que ha hecho que se modifiquen la estructura por edades de la población económicamente activa (PEA) de los países.

Las tasas de crecimiento de la Población Económicamente Activa (PEA) por edades específicas pronostican un claro envejecimiento, porque las cifras revelan que en los años noventa, la PEA creció a un ritmo medio anual de aproximadamente 6 millones de personas, de las cuales casi el 55\% eran menores de 40 años, no obstante, el grupo que más aumentó fue el de 40-65 años. En la década 2000, se estima un crecimiento medio anual de 5,5 millones de personas, 
de las cuales el 58\% tiene 40 años y más, y el grupo mayor de 65 años es el que aumenta más rápidamente. En los próximos periodos se proyecta una expansión de poco más de 4,7 millones de personas al año. (CEPAL, 2008:23) (Ver Figura No.1). Asimismo se vislumbra como la tasa de crecimiento de los de 65 años y más tiene su punto máximo en el 2020 pero, después de ese año se proyecta una leve disminución la cual irá tendiendo a ser constante.

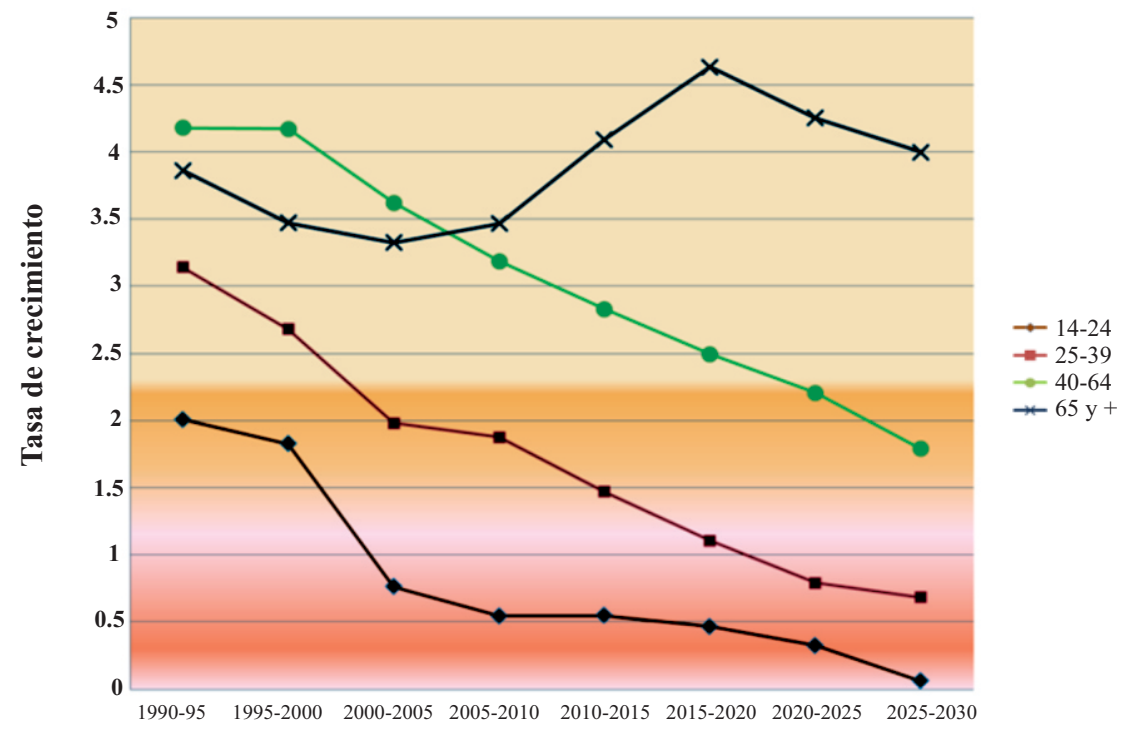

E\&A

IIES

Figura No.1

América Latina: Tasa de crecimiento de la población económicamente activa según grupos de edad 1990-2030

(por cien)

Fuente: Elaboración propia en base a los datos del Centro Latinoamericano y Caribeño de Demografía

(CELADE) Observatorio demográfico: Población económicamente activa No 2, 2006

Asimismo por su heterogeneidad en el proceso de envejecimiento, la proporción de adultos mayores en la actividad económica es cada vez más significativa, en cambio en los países desarrollados no sucede igual. Un ejemplo de ello es, Estados Unidos que en 1999, solo registraba el 17\% de hombres y 9\% de mujeres mayores de 65 años que seguían participando en la actividad económica, por el contario, en México según el censo del 2000 el 67\% de los hombres y el 43\% de las mujeres mayores de 60 años permanecían activas. Al analizar los datos por zona de residencia se observa que las tasas de participación disminuyen según avanza la edad, como sucede en Bolivia donde más del $60 \%$ de los adultos mayores 
Vol. 4

E\&A

IIES

residentes en el área urbana está activo; mientras que en la zona rural apenas llega al 38\%(CEPAL, 2004).

Estas cifras están sujetas a algunos factores que provocan que las personas en edad permanezcan insertas en la actividad económica, siendo estos: el ingreso percibido por la pensión sea muy bajo o que su inserción al mercado laboral haya sido tardío y no tenga los años de cotización suficientes para su retiro. Por lo tanto, se especula que los adultos mayores no permanecen voluntariamente en el mercado laboral sino, que lo hacen debido a su situación de vulnerabilidad socioeconómica.

\section{METODOLOGÍA}

Para el desarrollo del presente trabajo se utilizaron datos provenientes de la Base de Datos de la XLIII Encuesta Permanente de Hogares de Propósitos Múltiples Mayo, 2012 (EPHPM), la unidad de análisis las personas mayores de 60 años y es un análisis descriptivo. Para obtener los datos referente a la unidad de análisis se auxilió del paquete computacional SPSS. Se eligió la Encuesta de Hogares porque es la fuente que contiene los datos más recientes de la población referentes al mercado laboral y de esta manera construir los indicadores socio demográficos y socioeconómicos más relevantes (INE, 2012).

La Encuesta en particular no define el concepto de "Adultos Mayores" sino que dicho concepto se asignó en base a la definición universalmente aceptada de Adultos Mayores, que designa a las personas mayores de 60 años y más.

Las variables consideradas para este estudio son: categoría ocupacional, condición de actividad económica, situación de empleo, rama de actividad, ingresos y horas semanales trabajadas.ose así, el interés entre los demógrafos del país en el estudio del tema. 


\section{DIAGNÓSTICO NACIONAL DEL PROCESO DE ENVEJECIMIENTO EN HONDURAS}

\subsection{Envejecimiento de la Población Hondureña}

Honduras al igual que los demás países latinoamericanos, presenta un constante crecimiento en su población adulta mayor, producto de la reducción leve de la fecundidad y de un ritmo un poco más pronunciado de la mortalidad lo que la sitúa en una etapa de plena transición demográfica y en un proceso de envejecimiento moderado, como se explicó en el acápite anterior, produciéndose así, el interés entre los demógrafos del país en el estudio del tema.

En el estudio sobre el envejecimiento de la población hondureña escrito por Elvis Trejo, se señala que el índice de envejecimiento de la población hondureña para el año 2001 (año censal) era de 13.9\%, esto significa que de cada 100 jóvenes menores de 15 años habían 14 personas adultos mayores (Trejo, 2005). En la actualidad, según datos de la XLIII Encuesta Permanente de Hogares de Propósitos Múltiples (EPHPM) mayo 2012, estiman que el índice de envejecimiento ha aumentado a $20.5 \%$ y según las proyecciones de CELADE llegara a 100.4 en 2050. El incremento sostenido y creciente de este indicador es producto de la evolución obtenida en la fecundidad y mortalidad desde 1950 cuando los logros sociales y sanitarios que se dieron en esa época. (Ver Figura No.

2).

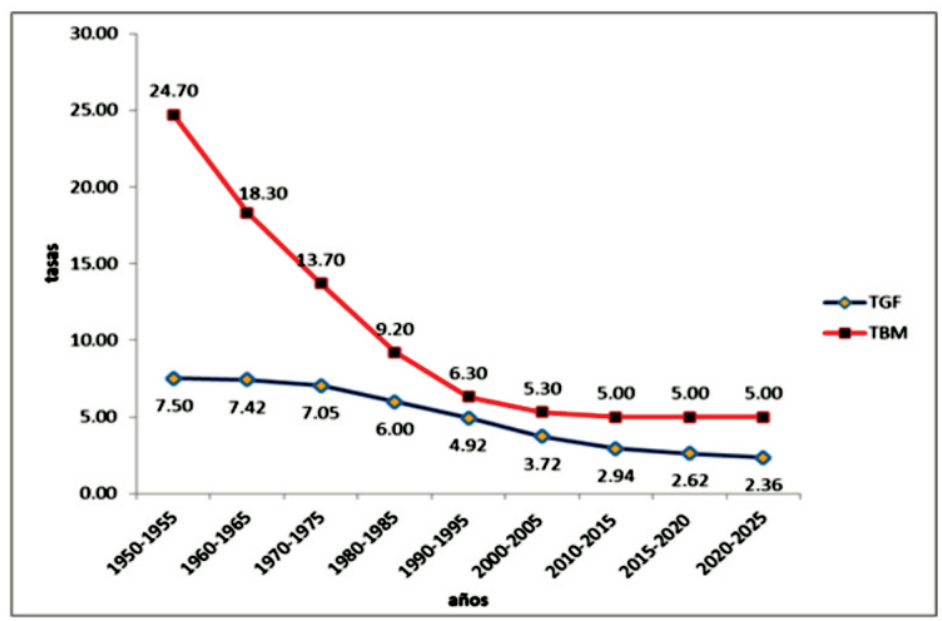

Figura No. 2

Honduras: Evolución de la Tasa Global de Fecundidad y la Tasa Bruta de Mortalidad, 1950-2025

Fuente: Elaboración propia en base a los datos del Observatorio demográfico $\mathrm{N}^{\circ} 12$ Envejecimiento poblacional. CEPAL América Latina y el Caribe. 
Vol. 4 $\mathrm{N}^{\circ} 1$ 2013

E\&A

IIES

La dinámica de las dos variables demográficas mostradas en el grafico anterior revela el lento descenso de la fecundidad hondureña comparado con el ritmo mucho mayor de la mortalidad ocasionando con ello un crecimiento acelerado de la población y un aumento en la esperanza de vida al nacer.

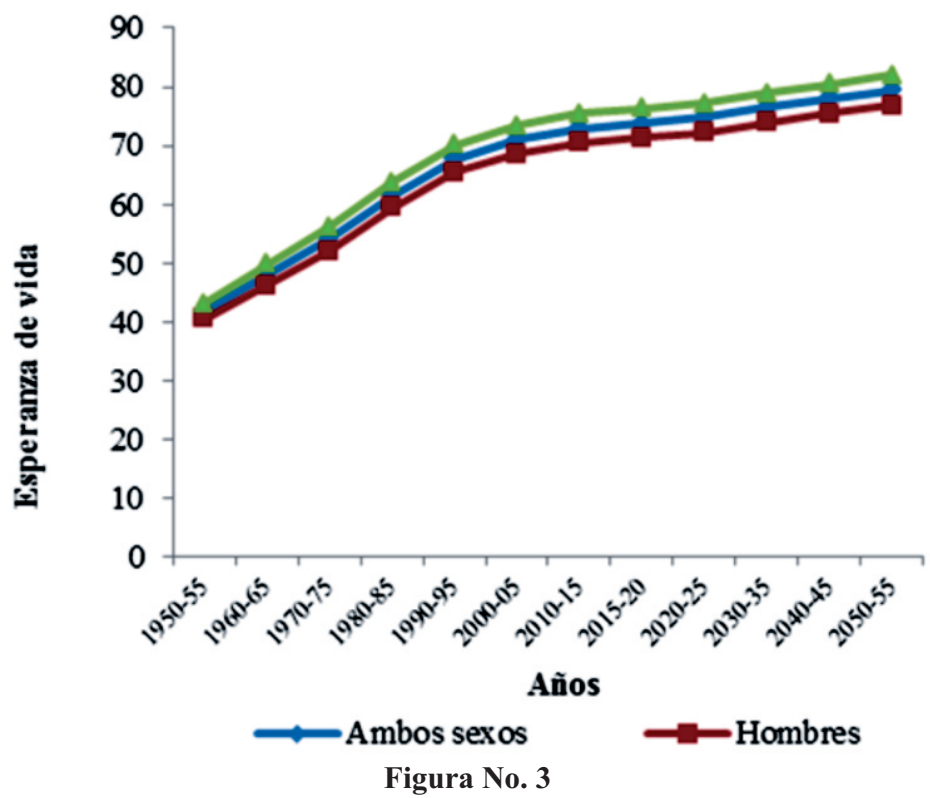

Honduras: Evolución de la Esperanza de vida al nacer por sexo, 1950-2050

Fuente: Elaboración propia en base a los datos del Observatorio demográfico $\mathrm{N}^{\circ} 12$ Envejecimiento poblacional. CEPAL América Latina y el Caribe

El grafico anterior muestra la evolución de la esperanza de vida al nacer y se observa que en el período de 1950-55 la brecha entre hombres y mujeres era muy pequeña 40.5 y 43.5 ) respectivamente, sin embargo en la actualidad, esa diferencia ha crecido lo que se induce que los efectos de la transición demográfica (pasar de altas tasas de fecundidad y mortalidad a bajas tasas) se hacen notorios al ampliarse la brecha de la esperanza de vida entre hombres y mujeres (70.5 y 75.4) y se supone que tal diferencia se mantendrá hasta el 2050. (Figura No. 3).

El aumento de la esperanza de vida tendrá impactos tanto sociales como económicos en el país, porque las personas demandarán programas en la seguridad social, la salud, el empleo, la educación, etc. Donde, la población mayor demandará también políticas de orden social como los de salud, casas de cuidados, entre otros. 
Cabe señalar que el aumento de la esperanza de vida ha provocado que el proceso de envejecimiento en Honduras avance de forma moderada porque todavía la estructura de su población continua siendo predominantemente joven, debido a la evolución de la fecundidad en épocas pasadas.

Un indicador importante en el proceso de envejecimiento de la población, es la razón de dependencia o relación de dependencia. Este indicador mide el número personas en edades en las que "dependen" (generalmente personas menores de 15 y mayores de 64 años de edad) de personas en edades "económicamente productivas" (entre 15 y 64 años de edad) (Haupt y Kane, 2003). Este indicador está relacionado con el cambio en la estructura por edad al igual que el índice de envejecimiento porque dependen de la dinámica de la fecundidad. Por otro lado, se destaca el crecimiento acelerado de la fecundidad la a mediados del siglo XX, por lo cual la relación de dependencia fue elevada, en el 2050, por la reducción de la fecundidad este indicador llegará a disminuir a valores menores de 60 , por ello nuestro país debe de prepararse para enfrentar este fenómeno llamado "bono demográfico" pues como se expresó anteriormente las personas mayores ejercerán presión en demandar la atención en salud, en la protección social, etc.

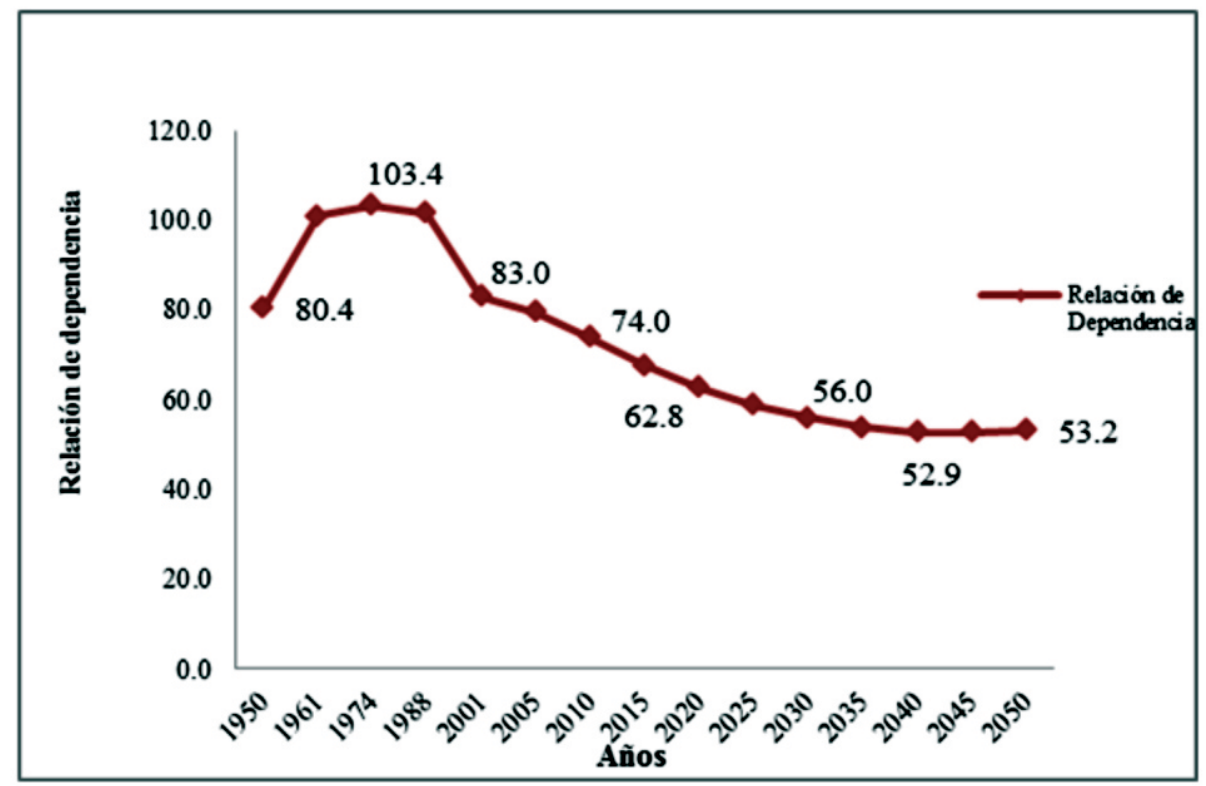

Figura No.4

Honduras Evolución de la Relación de Dependencia, 1950-2050

Fuente: Elaboración propia en base a proyecciones de la población de CELADE, 2011. 


\subsection{Características de la Población Adulta Mayor Hondureña}

Vol. 4

E\&A

IIES

60

El aumento continuo de la población hondureña principalmente en el grupo de los adultos mayores, representa un desafío para las políticas públicas del país. En solo la primera década del presente siglo dicha población paso de 419,474 a 786,016 habitantes (2002-2012) de los cuales el $44.5 \%$ pertenecen al sexo masculino y el $55.5 \%$ al femenino. renresentando a la vez el $9.5 \%$ de la noblación total. (Figura No.5).

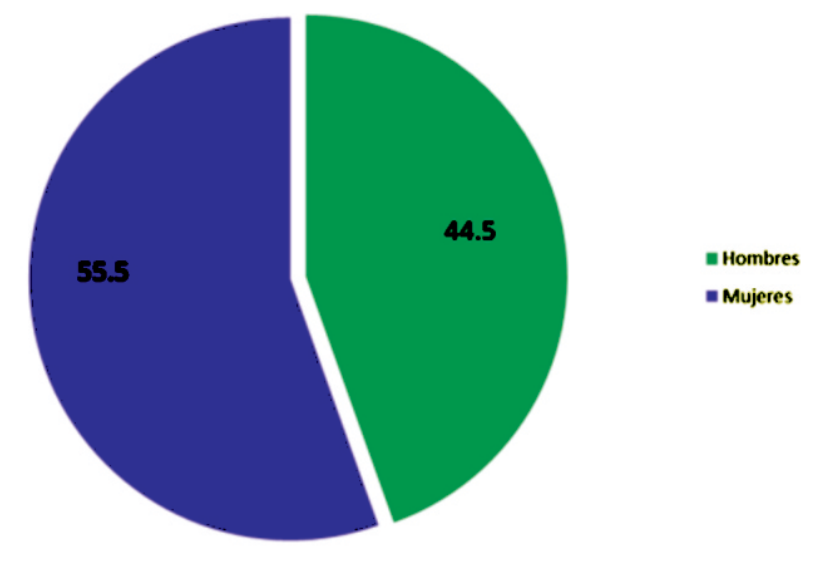

Figura No.5

Honduras: Distribución Relativa de los Adultos Mayores, 2012

Fuente: Elaboración propia en base a los datos de la XLIII Encuesta Permanente de Hogares y Propósitos Múltiples, INE, mayo, 2012

Tanto en el área rural como en la urbana vive el 50\% de la población en estudio, aunque en el área rural hay mayores niveles de fecundidad, convirtiéndose en un crecimiento natural pero que es compensado por las altas tasas de migración que el área rural experimenta (INE, 2012).

Producto del proceso de envejecimiento que el país atraviesa, la base de la pirámide se ha estrechado y la cúspide se ha ido expandiendo, de esta forma ha provocado una disminución en la población infantil y un aumento en los adultos mayores. Se espera que para el 2025 la población adulta mayor sea de 878,529 y para el 2050 de 2, 263,915 y con una esperanza de vida cercana a los 80 años.

En la Tabla No.1, se aprecia la estructura porcentual por edad de los adultos mayores, descubriéndose entre los datos de la encuesta de hogares, (Mayo 2012) 
que un poco más de la mitad de los adultos mayores alcanzan edades de 60-69 años, por tanto el proceso de envejecimiento está inmerso en la población hondureña, sin embargo, países como: México, Cuba y Argentina presentan un mayor avance en su proceso de envejecimiento, en vista de que la población en este intervalo de edad es mayor que la de Honduras.

Tabla No. 1

Honduras: Población Adulta Mayor, 2012

\begin{tabular}{|c|c|c|}
\hline $\begin{array}{c}\text { Grupos quinquenales edades } \\
\text { mayores }\end{array}$ & $\begin{array}{c}\text { Población } \\
\text { Adulta Mayor }\end{array}$ & \% \\
\hline $60-64$ & 219877 & 28.0 \\
\hline $65-69$ & 181452 & 23.1 \\
\hline $70-74$ & 136253 & 17.3 \\
\hline $75-79$ & 116508 & 14.8 \\
\hline $80-84$ & 72902 & 9.3 \\
\hline $85 \mathrm{y}+$ & 59024 & 7.5 \\
\hline & 786016 & 100.0 \\
\hline
\end{tabular}

Fuente: Elaboración propia en base a los datos de la XLIII Encuesta

Permanente de Hogares y Propósitos Múltiples, INE, mayo, 2012

Por los datos mencionados anteriormente es evidente el envejecimiento de la población pues la población mayor de 80 años está aumentando, predominando al igual que los demás países el sexo femenino, debido a la mayor esperanza de vida. (Figura No. 6).

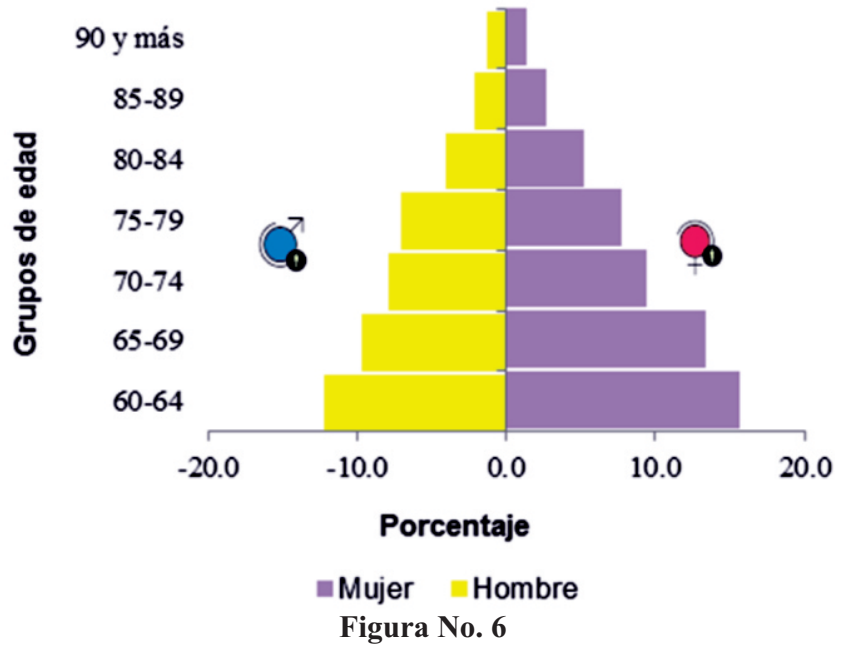

Honduras: Estructura Porcentual de Población Adulta Mayor por Grupos de Edad según Sexo, 2012

Fuente: Elaboración propia en base a los datos de la XLIII Encuesta Permanente de Hogares y Propósitos Múltiples, INE, mayo, 2012 
Vol. 4

E\&A

IIES

62

\section{SITUACIÓN LABORAL DE LOS ADULTOS MAYORES DE HONDURAS}

El aumento de la población adulta mayor en Honduras es evidente y a consecuencia de ello, es que se analiza a continuación la participación de este grupo etario de la población en el mercado laboral. El estudio de la población económicamente activa adulta mayor reviste de suma importancia porque se trata de los recursos humanos disponibles para la producción; aunque sea esta una población que forma parte de los grupos vulnerables.

Por otra parte y debido a la poca cobertura de las pensiones y sistemas de jubilación, los adultos mayores recurren a una serie de estrategias que les permiten mantener una fuente de ingresos y así contar con recursos para satisfacer sus necesidades personales. Una de ellas es mantenerse económicamente activos, lo cual contribuye a explicar las altas tasas de participación económica que se presentan en las edades avanzadas, particularmente entre los hombres. Porque según lo expresa Guzmán en su estudio "La seguridad económica de las personas mayores es la capacidad de disponer y usar de forma independiente una cierta cantidad de recursos económicos regulares, en montos suficientes para asegurar una buena calidad de vida en la vejez" (Guzman, 2002).

En este apartado se describirá la situación laboral que afrontan los adultos mayores y como participan del mercado laboral este segmento de la población, en vista de que la permanencia de los adultos mayores en el mercado laboral se ve influenciada por diferentes factores, entre ellos se encuentran el nivel educativo, la situación conyugal, la trayectoria laboral, ingreso y los programas de seguridad social.

\subsection{Población Económicamente Activa por Edad y Sexo}

La población económicamente activa (PEA) de Honduras es joven pues el 62.6\% de ésta es menor de 40 años y sólo el 10\% de esta categoría es mayor de 60 años. La población económicamente activa adulta mayor según la XLIII Encuesta Permanente de Hogares y Propósitos Múltiples (EPHPM) asciende a 321,669 lo que significa el $42 \%$ de la población avanzada, la cual está representada por el $67.7 \%$ y el $32.3 \%$ de hombres y mujeres respectivamente (INE, 2012). Tal como se observa en el Tabla No.2, de acuerdo a la estructura por edad, se encontró que más del $60 \%$ se concentra en grupos menores de 70 años, observándose además que el grupo de 70-74 años reúne a aproximadamente el 17\% de la PEA adulta mayor. 
Tabla No. 2

Honduras: Población Económicamente activa Adulta Mayor por Grupos de Edad y Sexo, 2012

\begin{tabular}{|c|c|c|c|}
\hline $\begin{array}{c}\text { Grupos de } \\
\text { Edad }\end{array}$ & Hombres & Mujeres & Total \\
\hline $60-64$ & 24.7 & 14.0 & 38.7 \\
\hline $65-69$ & 17.4 & 8.2 & 25.6 \\
\hline $70-74$ & 12.4 & 4.4 & 16.8 \\
\hline $75-79$ & 8.1 & 3.7 & 11.8 \\
\hline $80-84$ & 3.9 & 1.3 & 5.2 \\
\hline $85 \mathrm{y}+$ & 1.2 & 0.6 & 1.8 \\
\hline Total & 67.7 & 32.3 & 100.0 \\
\hline
\end{tabular}

Fuente: Elaboración propia en base a los datos de la XLIII Encuesta Permanente de Hogares y Propósitos Múltiples (EPHPM) mayo 2012

Además se aprecia que tanto la PEA masculina como la femenina se concentran en los grupos de edad de 60-69 años, en más de un 40\% y 20\%. Asimismo se estima una sobrerrepresentación de los hombres en todas las edades siendo mayor la proporción en el grupo de 60-64 años. (Figura No.7).

También se observa que a medida avanza la edad, disminuye la inserción en el mercado laboral tanto en hombres como en mujeres pero, el descenso es más fuerte en la mujer. Es importante mencionar que, aunque en estas edades se inicia la edad de retiro, hay personas que mantienen su independencia económica, sobre todo en las personas del rango de edad de 60-74 años, la cual puede estar influenciada por los bajos ingresos percibidos de la jubilación así como por los deseos de permanecer activos.

Por otra parte, aunque la mujer va ganando espacio en el mercado de trabajo aún es marcadamente sub representada, debido a que históricamente se le ha asignado a la mujer el rol reproductivo y maternal, mientras al hombre el trabajo productivo remunerado.

En general, la estructura por edad de la PEA de ambos sexos presenta sus diferencias, en vista de que en algunos grupos de edad el hombre dobla y en otros hasta triplica su participación en el mercado laboral con respecto a la mujer. Lo que significa que de cada 3 hombres insertos en el mercado laboral existe 1 mujer. 
Vol. 4

E\&A

IIES

64

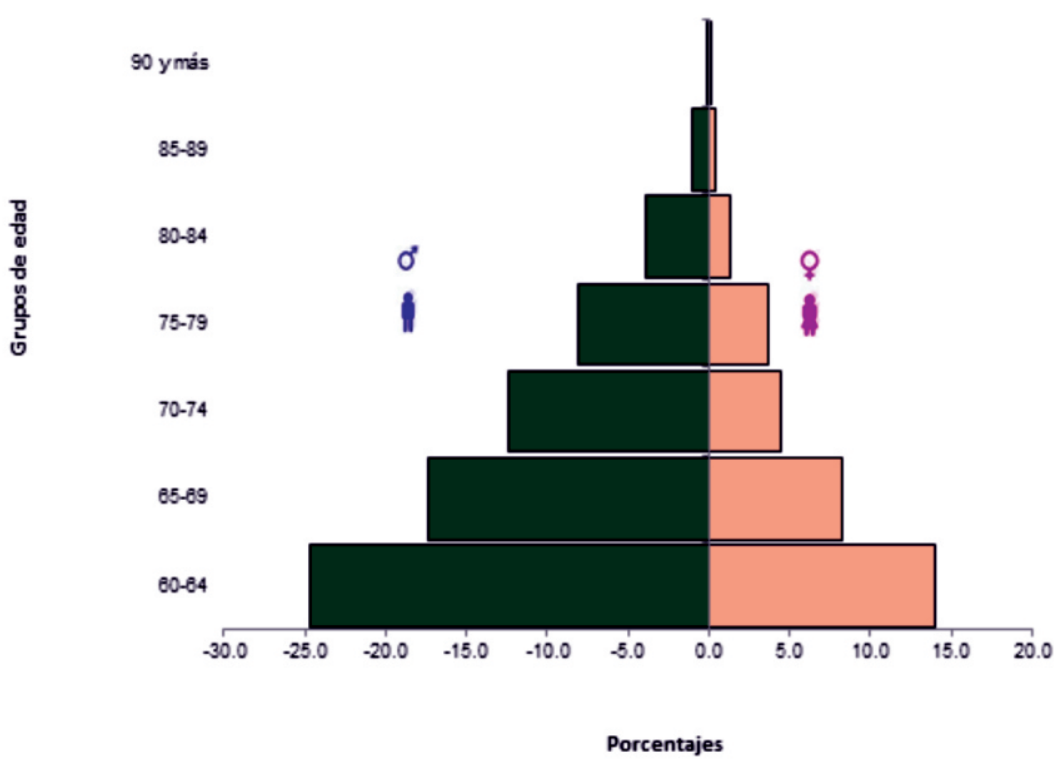

Figura No.7

Honduras: Población Económicamente Activa Adultos Mayores por sexo, 2012.

Fuente: Elaboración propia en base a los datos de la XLIII Encuesta Permanente de Hogares y Propósitos Múltiples (EPHPM) mayo 2012

\subsection{Población Económicamente Activa por Área de Residencia}

En la misma fuente de datos, se observa una alta concentración de la PEA adulta mayor en el área rural, en vista de eso tenemos que dicha población se distribuye en $43.2 \%$ y $56.8 \%$ en el área urbana y rural respectivamente. La permanencia en el mercado laboral es mayor en el área rural por varias razones, en primer lugar, por la migración interna que las personas más jóvenes realizan a las ciudades, en busca de mejores oportunidades ya sea por empleo y/o educación; afectando de esta manera a las personas en edades avanzadas pues no existe la suficiente mano de obra para ocuparse de las actividades agropecuarias, y en segundo lugar por la baja cobertura en la seguridad social.

A la vez se muestra que tanto en el área urbana como en la rural se concentran en los grupos menores de 75 años, así como sucede a nivel nacional. La PEA urbana reúne a más del $35 \%$ y la PEA rural a más del $45 \%$. Es importante señalar el aumento del porcentaje del grupo de 65-69 y 70-74 años en el área rural con respecto a la urbana al pasar de un $10.6 \%$ a un $15 \%$ y de un $6.7 \%$ a un $10.1 \%$ respectivamente. 
En la figura siguiente se puede apreciar la constante ruralización de la población económicamente activa de ambos sexos en todos los grupos de edad.

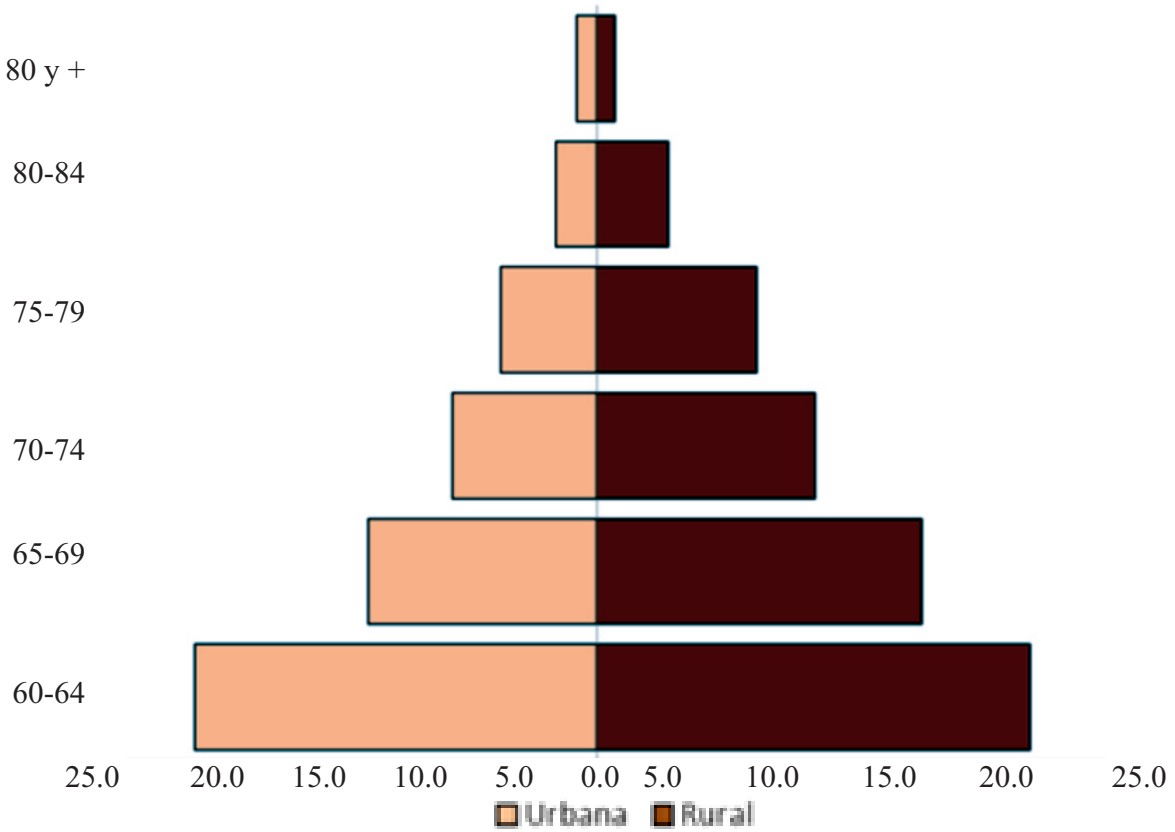

E\&A

IIES

Figura No. 8

Honduras: Pirámide de la PEA Adulta Mayor por Área

Fuente: Elaboración propia en base a los datos de la XLIII Encuesta Permanente de Hogares y Propósitos Múltiples (EPHPM) mayo 2012

Al separar los datos por sexo, el área rural concentra al $74.1 \%$ de hombres y el $25.9 \%$ de mujeres, estas cifras tienen relación con la tenencia de la tierra, en vista que en su mayoría los hombres son los dueños de la misma. El área urbana, aglutina al $59.3 \%$ de hombres y al y $40.7 \%$ de mujeres. Teniendo en cuenta estos datos se puede afirmar que, los hombres permanecen más tiempos insertos en el mercado laboral que las mujeres, porque las mujeres interrumpen las actividades económicas en algún momento de su vida. (Ver Tabla No. 3). 
Tabla No. 3

Honduras: Población Adulta Mayor Económicamente Activa por Área de Residencia según Sexo, 2012

Vol. 4 $\mathrm{N}^{\circ} 1$ 2013

E\&A IIES

\begin{tabular}{|l|l|l|}
\hline & \multicolumn{2}{|l|}{ PEA } \\
\hline Sexo & Urbana & Rural \\
\hline Hombre & 59,3 & 74,0 \\
\hline Mujer & 40,7 & 26,0 \\
\hline Total & 100 & 100 \\
\hline
\end{tabular}

Fuente: Elaboración propia en base a los datos de la XLIII Encuesta Permanente de Hogares y Propósitos Múltiples (EPHPM) mayo 2012

Al analizar la distribución de la PEA por dominio (Distrito Central, San Pedro Sula, ciudades medianas, ciudades pequeñas y rural) se encontró que las dos principales ciudades del país; Distrito Central y San Pedro Sula aglutinan a 50,811 adultos mayores activos donde el $61.7 \%$ son hombres y el $38.2 \%$ a mujeres.

\subsection{Tasas de Participación Económica}

Cuando se analiza la participación económica de los adultos mayores, se hace a través de la tasa bruta de participación, el cual resulta de mucha muy útil porque mide el grado de participación económica que tienen los adultos mayores en la PEA.

En la literatura consultada, se encontró que existen datos que reflejan que en el periodo de 2001-2010 el promedio de los adultos mayores hondureños que estaban activos era de $46.1 \%$ (Zelaya, 2011), en la actualidad la tasa de participación es de $42.2 \%$, este descenso puede estar siendo provocado por la crisis económica que atraviesa el país, en vista que, las empresas han disminuido su participación laboral a los adultos mayores pues tienden a subestimarlo prefiriendo con ello a la población joven, la cual es contratada con salarios bajos y por una jornada de trabajo más prolongada.

Al separar los datos por sexo, los hombres tienen mayor participación que las mujeres $67.3 \%$ y $32.7 \%$ respectivamente, reflejando con ello que los hombres permanecen más tiempo en el mercado laboral que las mujeres, en vista que ellas en algún momento de su vida tuvieron que descontinuar sus actividades laborales por ocuparse a su rol maternal teniendo después la dificultad de volver a insertarse en el mismo. 
Por otra parte al comparar los datos de la tasa de participación de Honduras con la de otros países de América Latina y expuestos en el gráfico siguiente, se perciben algunas tendencias: que a excepción de Bolivia los tres países restantes presentan aumentos en la tasas de participación después de la primera década del siglo XXI; en segundo lugar, Bolivia y Honduras tienen niveles similares aunque Bolivia supera a Honduras en casi 10 puntos porcentuales (pp) en todos los años; en tercer lugar, Costa Rica y Cuba tienen niveles muy inferiores (como países desarrollados) al de los otros dos países, sosteniendo estos niveles a través del tiempo. Estos niveles bajos han provocado que se produzca una gran brecha entre estos dos últimos países y los dos primeros, al presentar tasas tan diferenciadas a pesar de estar los cuatro en el mismo continente; y en cuarto lugar, Cuba es el único país de los cuatro que a pesar de ser uno de los países con una población bastante longeva, no llega a participar de la actividad económica ni aun el veinte por ciento de este grupo etario.

Asimismo se puede afirmar que esta heterogeneidad palpable en las tasas de actividad de los países seleccionados puede estar influenciada por la etapa de transición demográfica que los mismos atraviesan, así como, al desarrollo en los programas de seguridad social como lo afirma (Grubel y Wise, 2004), porque el adulto mayor tiende a permanecer en el mercado de trabajo para mantener una fuente de ingresos que le permita satisfacer sus necesidades personales.

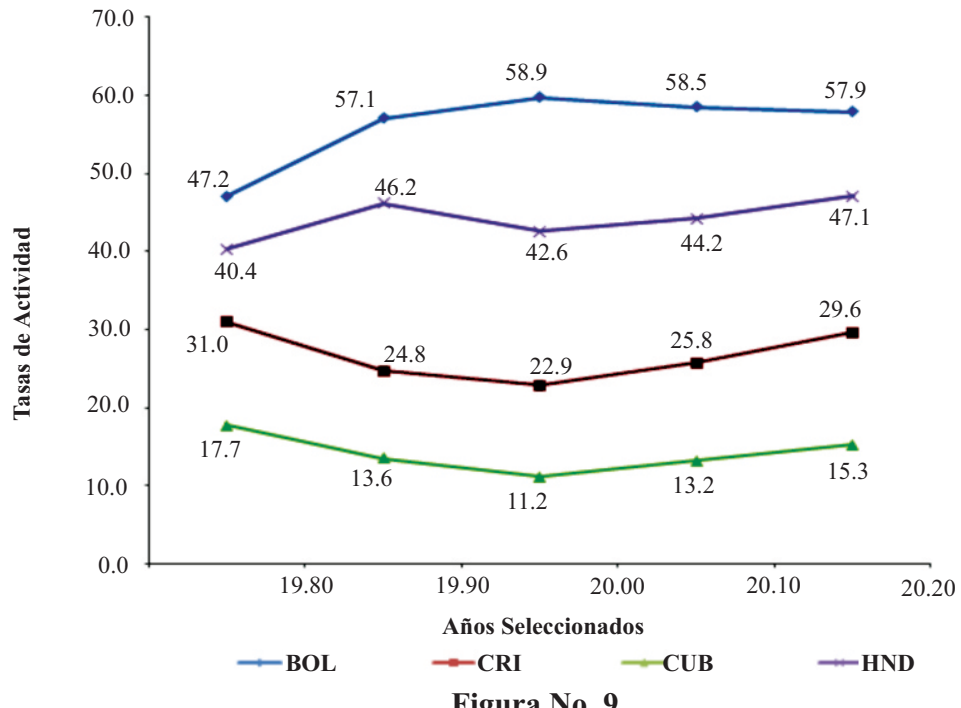

Figura No. 9

Tasas de actividad de países y años seleccionados

Fuente: Elaboración propia en base a los datos obtenidos de las estimaciones y proyecciones de población a largo Plazo. 1950-2100, CELADE, 2012. 
Vol. 4 $\mathrm{N}^{\circ} 1$ 2013

E\&A IIES

68

\subsubsection{Tasas Específicas de Participación por Edad y Sexo}

Al desagregar la tasa de participación (TP) por edad y sexo, se aprecia que a partir del año 2000 y antes de los sesenta años de edad las tasas de participación de los hombres empiezan a disminuir en los cuatro países; Honduras y Bolivia presentan las tasas masculinas cercanas a la edad retiro más altas de los cuatro países, estas son cercanas al 95 por ciento. Para el subgrupo de 60-64 y de 65 años y más, la tendencia es similar el promedio de las tasas masculinas oscilan entre el $85 \%$ y $60 \%$ respectivamente. Asimismo se observa que a medida que avanza la edad, la participación disminuye; y muestra como en el subgrupo de 75 años hay notables diferencias porque para el año 2010, en Costa Rica y Cuba la tasa de participación masculina no era superior al veinte por ciento, en cambio en Honduras y Bolivia eran superiores al 35 por ciento (Véase figura No.10).

Para el subgrupo de 60-64 y de 65 años y más, la tendencia es similar las tasas rondan el $85 \%$ y el $60 \%$ respectivamente.

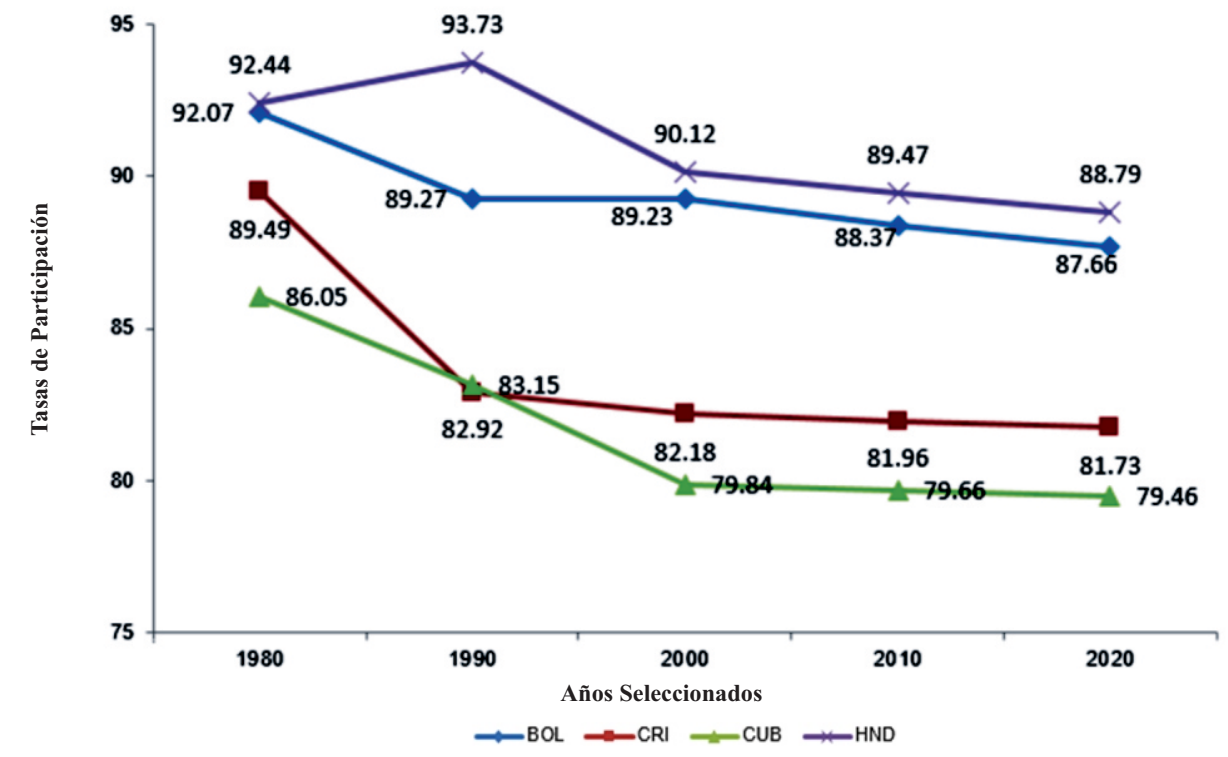

Figura No. 10a

Tasas de Participación Económica Específica por Edad y Sexo de países y años seleccionados, 19802020.- Hombres 55-59 años

Fuente: Centro Latinoamericano de Demografía (CELADE). Estimaciones y proyecciones de población a largo plazo. 1950-2100, Revisión 2012 


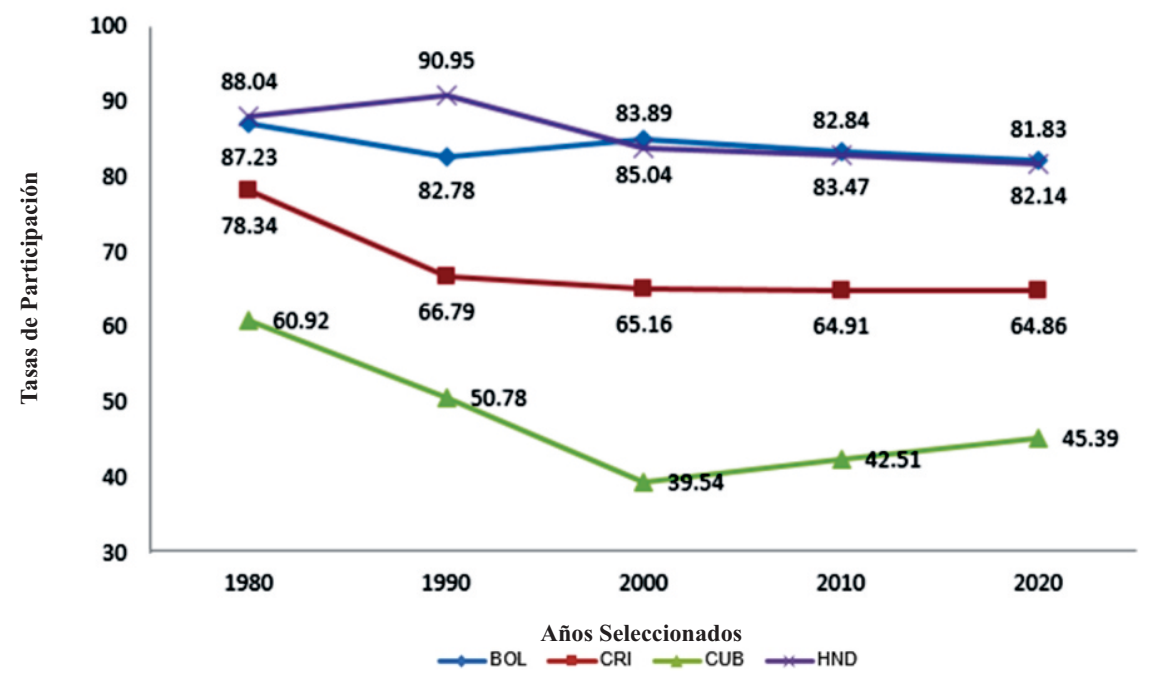

Figura No. 10b

Tasas de Participación Económica Específica por Edad y Sexo de países y años seleccionados, 19802020.- Hombres 60-64 años

Fuente: Centro Latinoamericano de Demografía (CELADE). Estimaciones y proyecciones de población a largo plazo. 1950-2100, Revisión 2012

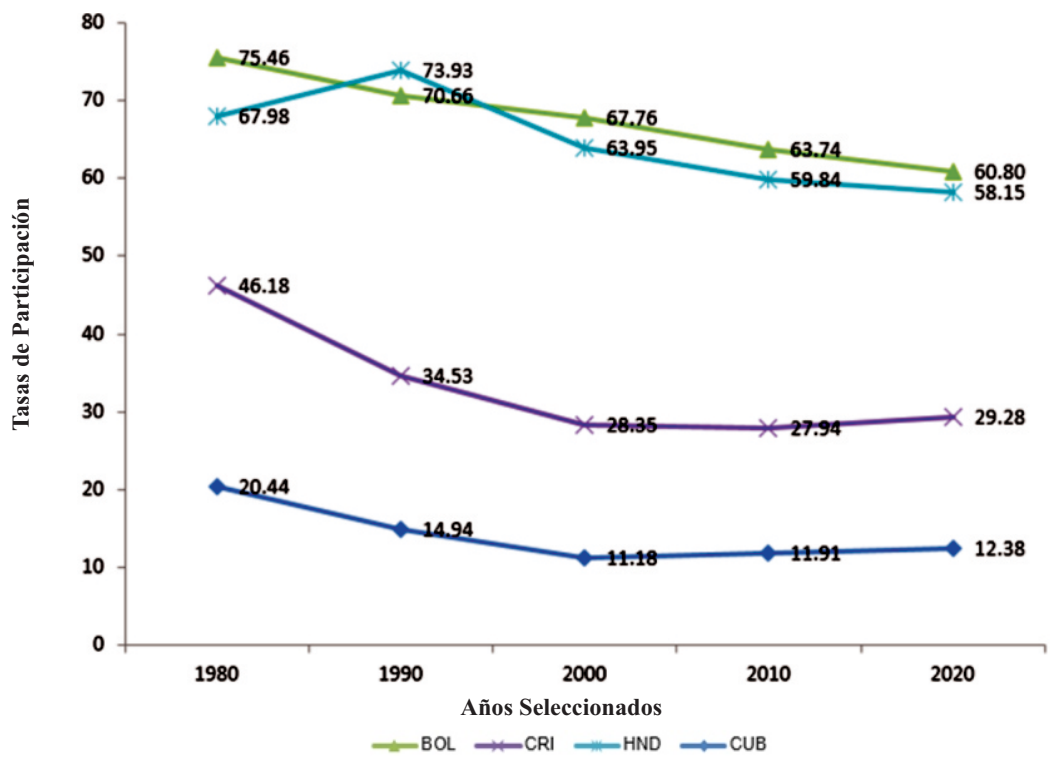

Figura No. 10c

Tasas de Participación Económica Específica por Edad y Sexo de países y años seleccionados, 1980-

2020.- Hombres $65 \mathrm{y}+$

Fuente: Centro Latinoamericano de Demografía (CELADE). Estimaciones y proyecciones de población a largo plazo. 1950-2100, Revisión 2012 
Vol. 4 $\mathrm{N}^{\circ} 1$

E\&A IIES

LA SITUACIÓN LABORAL DE LOS ADULTOS MAYORES EN HONDURAS

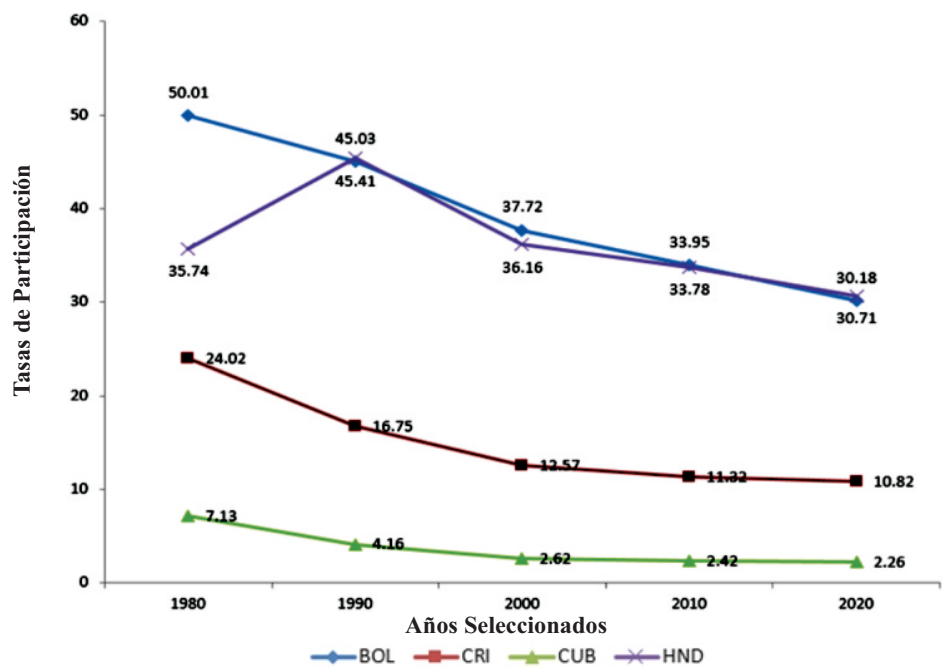

Figura No. 10d

Tasas de Participación de países y años seleccionados, 1980-2020.- Hombres 75 y +

Fuente: Centro Latinoamericano de Demografía (CELADE). Estimaciones y proyecciones de población a largo plazo. 1950-2100, Revisión 2012

En la Figura siguiente, se muestran las tendencias de las tasas de participación femeninas donde el comportamiento es muy diferente al de los hombres, porque en los grupos de 55-59 y 60-64 años, éstas han crecido desde 1980, siendo Bolivia el país que reporta los niveles más altos de participación. Cabe destacar que en ambos grupos Honduras presenta niveles muy similares a los de Costa Rica y Cuba (niveles bajos) donde para 2010, no eran mayores al 35 por ciento.

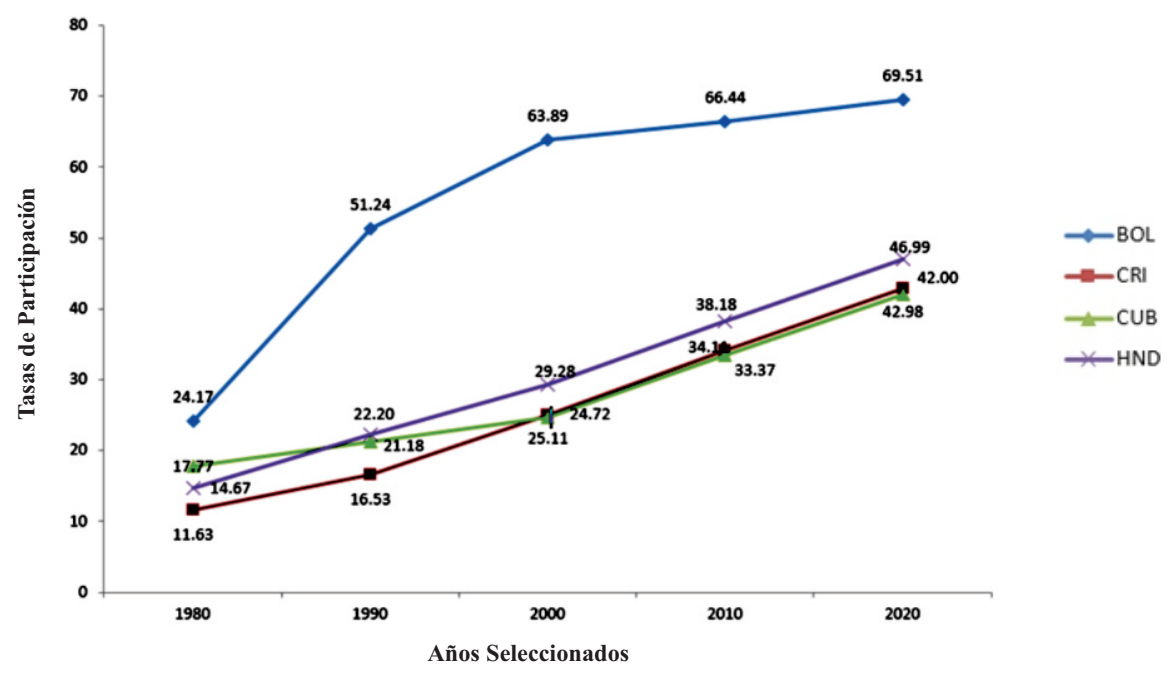

Figura No. 11a

Tasas de Participación Económica Específica por Edad y Sexo de países y años seleccionados, 19802020.- Mujeres 55-59

Fuente: Centro Latinoamericano de Demografía (CELADE). Estimaciones y proyecciones de población a largo plazo. 1950-2100, Revisión 2012 


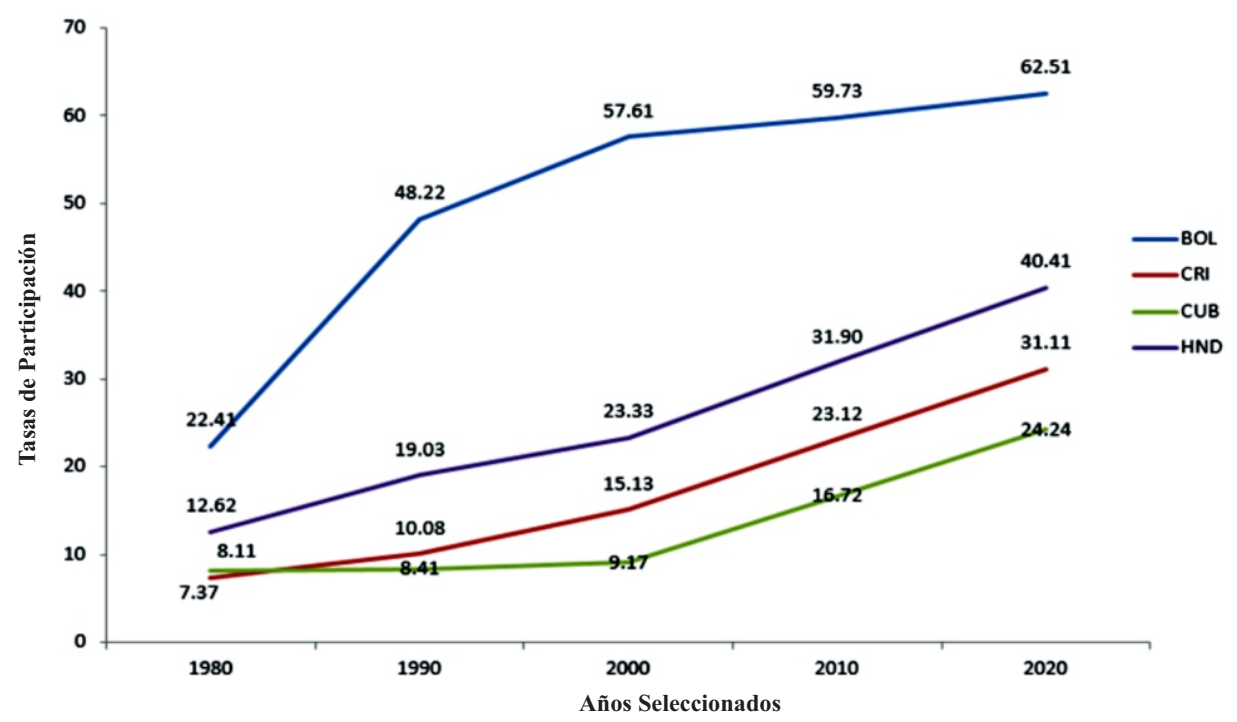

Figura No. 11b

Tasas de Participación Económica Específica por Edad y Sexo de países y años seleccionados, 1980-

2020.- Mujeres 60-65

Fuente: Centro Latinoamericano de Demografía (CELADE). Estimaciones y proyecciones de población a largo plazo. 1950-2100, Revisión 2012

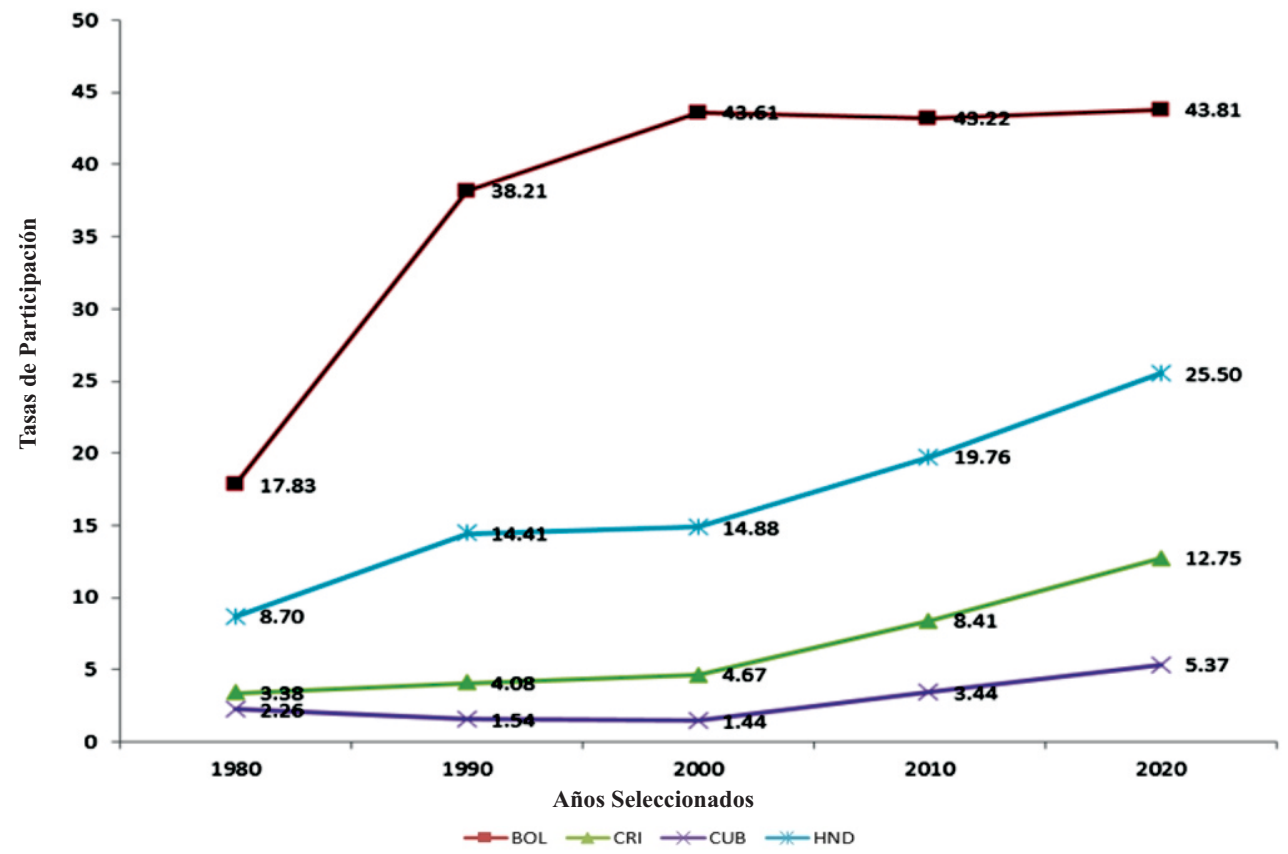

Figura No. 11c

Tasas de Participación de países y años seleccionados, 1980-2020. Mujeres 65 años y +

Fuente: Centro Latinoamericano de Demografía (CELADE). Estimaciones y proyecciones de población a largo plazo. 1950-2100, Revisión 2012 
Vol. 4 $\mathrm{N}^{\circ} 1$ 2013

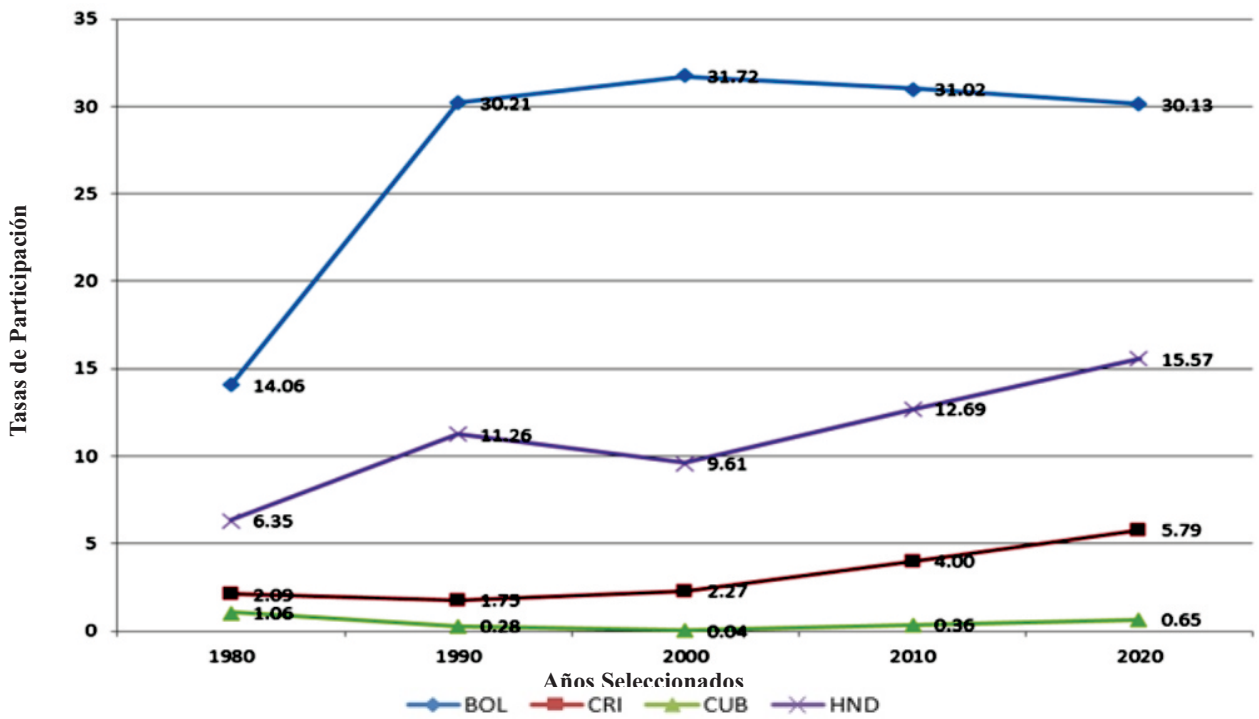

Figura No. 11d

Tasas de Participación de países y años seleccionados, 1980-2020. Mujeres 75 años y +

Fuente: Centro Latinoamericano de Demografía (CELADE). Estimaciones y proyecciones de población a largo plazo. 1950-2100, Revisión 2012

E\&A

IIES

En el grupo de 75 años y más la tendencia es diferente, la Figura muestra que las tasas de participación de Cuba disminuyen a partir de 1980 teniendo un comportamiento casi nulo de participación a lo largo del tiempo; en cambio en Honduras, la disminución solo ocurre en la última década del siglo pasado, para después continuar creciendo a comienzos del Siglo XXI con niveles alrededor del 15 por ciento. (Figura No.11).

Los datos mencionados anteriormente, revelan que existen diferencias en las tasas de actividad por género, pues las tasas de actividad femeninas suelen estar subestimadas porque muchas mujeres que se declaran inactivas trabajan, pero lo hacen en el sector informal de la economía, contribuyendo de esa manera al sustento económico del hogar.

Por otra parte, según la literatura consultada, consideran que la participación económica de los adultos mayores no es una opción voluntaria sino que surge de la escasez de opciones para enfrentar sus necesidades económicas, las cuales son muchas, sobre todo los altos costos que genera la atención en la salud. Asimismo se deja ver que los adultos mayores muchas veces tienen trabajos en condiciones precarias y sin ningún beneficio de seguridad social, especialmente las mujeres donde la mayoría de ellas realiza actividades en el sector informal. 


\subsection{PEA por Condición de Actividad}

En la Tabla No. 4 se presentan las condiciones de actividad por dominio, para la población de 60 años y más. Se observa que la mayoría de los hombres permanece empleado más tiempo, en cambio en las mujeres aproximadamente solo el $20 \%$ permanece empleado. Asimismo se estima que los mayores porcentajes de desocupados se encuentran en las dos ciudades principales del país (Distrito Central y San Pedro Sula). En la categoría de inactivos, se aprecia una mayor proporción en las mujeres, en todos los dominios considerados los cuales son cercanos al 80\%. También se encontró que hay mujeres que aunque están en edad de trabajar no lo hacen y después de los 65 años pasan a ser inactivas. En los hombres el rubro de desocupado o desempleado es más importante que en las mujeres, por ello muchas veces se declaran ocupados. importante que en las mujeres, por ello muchas veces se declaran ocupados.

Tabla No. 4

Honduras: PEA Adultos Mayores por Condición de Actividad según Dominio, 2012

\begin{tabular}{|l|l|r|r|r|r|r|}
\hline & & \multicolumn{4}{|c|}{ Dominio 4 } & \\
\hline \multirow{4}{*}{ Sexo } & $\begin{array}{l}\text { Condición } \\
\text { de Actividad }\end{array}$ & $\begin{array}{l}\text { Distrito } \\
\text { Central }\end{array}$ & $\begin{array}{c}\text { San Pedro } \\
\text { Sula }\end{array}$ & $\begin{array}{c}\text { Resto } \\
\text { Urbano }\end{array}$ & Rural & Total \\
\hline \multirow{4}{*}{ Hombre } & Ocupados & 46.5 & 49.3 & 54.9 & 73.5 & 63.6 \\
\cline { 2 - 8 } & Desocupados & 1.2 & 1.4 & 0.2 & 0.4 & 0.5 \\
\cline { 2 - 8 } & Inactivos & 52.3 & 49.3 & 44.9 & 26.0 & 35.9 \\
\cline { 2 - 7 } & Total & 100.0 & 100.0 & 100.0 & 100.0 & 100.0 \\
\hline \multirow{4}{*}{ Mujer } & Ocupados & 20.7 & 23.2 & 27.4 & 23.9 & 24.6 \\
\cline { 2 - 8 } & Inactivos & 79.3 & 76.8 & 72.6 & 76.1 & 75.4 \\
\cline { 2 - 8 } & Total & 100.0 & 100.0 & 100.0 & 100.0 & 100.0 \\
\hline \multirow{5}{*}{ Total } & Ocupados & 31.3 & 34.3 & 38.6 & 47.7 & 42.0 \\
\cline { 2 - 7 } & Desocupados & 0.5 & 0.6 & 0.1 & 0.2 & 0.2 \\
\cline { 2 - 7 } & Inactivos & 68.2 & 65.1 & 61.3 & 52.1 & 57.8 \\
\cline { 2 - 7 } & Total & 100.0 & 100.0 & 100.0 & 100.0 & 100.0 \\
\hline
\end{tabular}

Fuente: INE. Encuesta Permanente de Hogares y Propósitos Múltiples, mayo 2012.

En cuanto a las ocupaciones de los adultos mayores, no hay que perder de vista la diferenciación en el comportamiento por sexo. En casi todas las ocupaciones es mayor la proporción de hombres, especialmente en aquellas ocupaciones que tradicionalmente han sido ocupadas por ellos, por ejemplo en conductores de transporte. En los "Profesionales y Técnicos, le dobla a las mujeres al igual que en 
Vol. 4

E\&A

IIES

"Directores, Gerentes y Administrativos" y en "Trabajador Industrial, textil y albañiles". En otras ocupaciones como "Agricultores, Ganaderos y Trabajadores Agrícolas la relación es de 4 a 1. Las ocupaciones principales de las mujeres son aquellas que son propias de su género, como por ejemplo "Empleadas de Oficina" (secretarias, contadores, aseadoras), "Comerciantes y Vendedoras (principalmente las vendedoras informales o ambulantes) y Servicios personales (empleadas domésticas). Es interesante que algunas mujeres adultas mayores declararon que al momento de la encuesta habían buscado trabajo por primera vez (Figura No. 12).

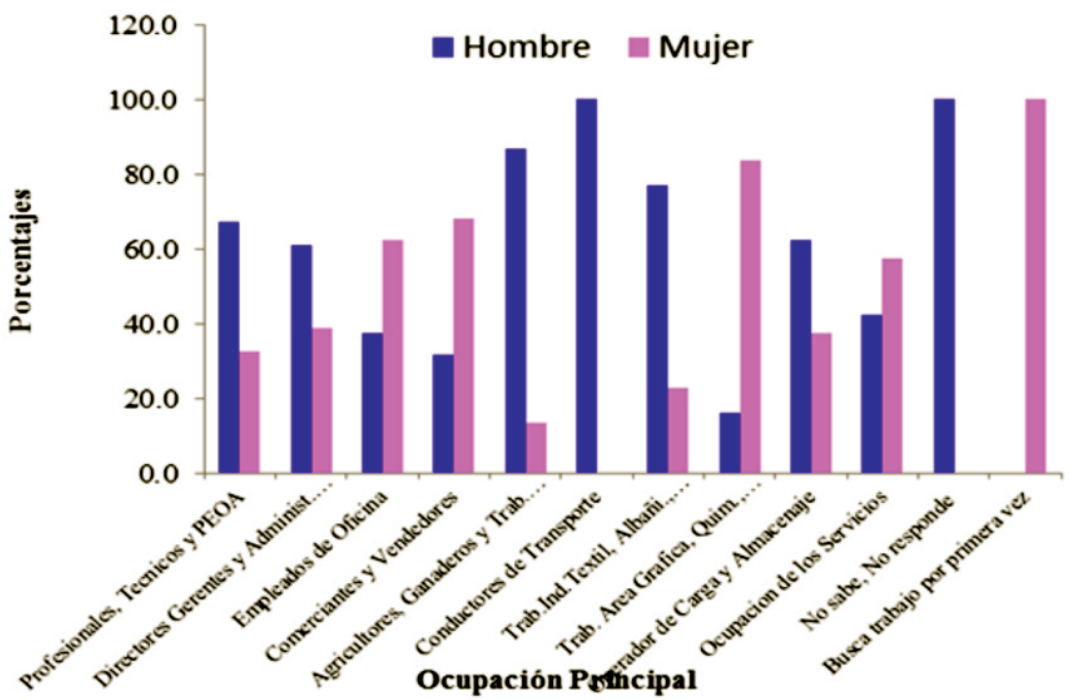

Figura No.12

Honduras: PEA adultos Mayores por Ocupación Principal según sexo, 2012

Fuente: INE. Encuesta Permanente de Hogares y Propósitos Múltiples, mayo 2012.

\subsection{PEA por Categoría Ocupacional}

Estudios recientes afirman que en los países en desarrollo, en términos de categoría ocupacional, los adultos mayores encuentran una oportunidad laboral en el empleo informal especialmente por el comportamiento de los hombres. (Bertranou, F., 2006).

En la Tabla No. 5 se confirma este hecho, la proporción de los trabajadores hondureños asalariados tiende a disminuir a medida que aumenta la edad y el porcentaje de los que trabajan por cuenta propia. 
En Honduras, el $46 \%$ de la población menor de 60 años es asalariada y el $42.3 \%$ está trabajando por cuenta propia, lo que hace que contraste con el $16.7 \%$ de los adultos mayores $(60$ años $\mathrm{y}+$ ) que son trabajadores asalariados contra el $80.5 \%$ por ciento de este mismo grupo que trabaja como cuenta propia.

Tabla No. 5

Honduras: PEA adulta mayor por Categoría Ocupacional, 2012

\begin{tabular}{|l|r|r|r|}
\hline $\begin{array}{c}\text { Grandes } \\
\text { grupos de } \\
\text { edad }\end{array}$ & Asalariados & \multicolumn{1}{|c|}{$\begin{array}{c}\text { Cuenta } \\
\text { Propia }\end{array}$} & $\begin{array}{c}\text { Trabajadores } \\
\text { no } \\
\text { remunerados }\end{array}$ \\
\hline $15-59$ & 46,0 & 42,3 & 11,7 \\
\hline $60-64$ & 34,0 & 75,9 & 1,5 \\
\hline $65-69$ & 16,9 & 80,1 & 3,0 \\
\hline $70 \mathrm{y}+$ & 10,3 & 85,9 & 3,7 \\
\hline
\end{tabular}

Fuente: INE. Encuesta Permanente de Hogares y Propósitos Múltiples, mayo 2012.

Al analizar la categoría ocupacional por sexo, se observa que los adultos mayores hombres están insertos en mayores proporciones en el sector privado y cuenta propia $(86.8 \%$ y $68.1 \%)$ respectivamente y las mujeres como empleadas domésticas y trabajador no remunerado, siguiéndole en su orden las empleadas públicas $(77.3 \%, 52.3 \%$ y $37.9 \%)$ respectivamente. Esto sucede porque los hombres tuvieron mejores oportunidades de emplearse en su vida activa y aún siguen participando del mercado laboral en estas categorías. Además, las mujeres en algún momento de su vida interrumpen su vida laboral, ya sea por maternidad, cuidado de los hijos o por otra causa de índole familiar. (Tabla No.6).

Tabla No. 6

Honduras: PEA Adultos Mayores según Categoría Ocupacional por sexo, 2012

\begin{tabular}{|l|c|c|c|}
\hline $\begin{array}{l}\text { Categoría Ocupacional } \\
\text { (Ocupación Principal) }\end{array}$ & Hombres & Mujeres & Total \\
\hline Empleado Publico & 62,1 & 37,9 & 100,0 \\
\hline Empleado Privado & 86,8 & 13,2 & 100,0 \\
\hline Empleada Domestica & 22,7 & 77,3 & 100,0 \\
\hline Cuenta Propia & 68,1 & 31,9 & 100,0 \\
\hline Trabajador no Remunerado & 47,7 & 52,3 & 100,0 \\
\hline Total & 69,1 & 30,9 & 100,0 \\
\hline
\end{tabular}

Fuente: Encuesta Permanente de Hogares y Propósitos Múltiples. INE, mayo 2012 
Vol. 4 $\mathrm{N}^{\circ} 1$ 2013

E\&A IIES

Estos porcentajes tienen relación tanto con la categoría ocupacional como con la condición de actividad, pues en los países en desarrollo a medida que las personas avanzan en edad participan en el mercado laboral como cuenta propia. La única ocupación.

\subsection{PEA por Rama de Actividad Económica}

La información de la Tabla No.7 ilustra la distribución de la PEA por rama de actividad económica. Como era de esperar los datos reflejan una preferencia por la "Agricultura, Silvicultura, Caza y Pesca porque dicho rubro alcanza porcentajes cercanos al 50\%. Aunque algunas veces esta actividad se haya visto afectada por los desastres naturales, por el deterioro de la tierra y/o por la mecanización en el agro. La rama de "Comercio y Servicio" es la segunda de mayor importancia, la cual presenta un porcentaje de $22.2 \%$ y en tercer lugar "Servicios Comunales, Sociales y Personales" (10.9\% respectivamente).

Tabla No.7

Honduras: PEA Adultos Mayores según Rama de Actividad, 2012

\begin{tabular}{|l|c|c|}
\hline \multicolumn{1}{|c|}{$\begin{array}{c}\text { Rama de actividad económica } \\
\text { (Ocupación Principal) }\end{array}$} & Total & $\mathbf{\%}$ \\
\hline Agricultura, Silvicultura, Caza y Pesca & 158229 & 49,2 \\
\hline Explotación de minas y canteras & 749 & 0,2 \\
\hline Industria manufacturera & 30828 & 9,6 \\
\hline Electricidad, gas y agua & 1489 & 0,5 \\
\hline Construcción & 10084 & 3,1 \\
\hline $\begin{array}{l}\text { Comercio por Mayor/Menor, } \\
\text { Hoteles/Restaurantes }\end{array}$ & 71391 & 22,2 \\
\hline $\begin{array}{l}\text { Transporte almacenamiento y } \\
\text { comunicaciones }\end{array}$ & 4727 & 1,5 \\
\hline $\begin{array}{l}\text { Establecimientos financieros. seguros, } \\
\text { Bienes inmuebles y servicios }\end{array}$ & 5597 & 1,7 \\
\hline $\begin{array}{l}\text { Servicios Comunales, Sociales y } \\
\text { Personales }\end{array}$ & 35060 & 10,9 \\
\hline Busca Trabajo por Primera Vez & 3515 & 1,1 \\
\hline Total & 321669 & 100,0 \\
\hline
\end{tabular}

Fuente: INE. Encuesta Permanente de Hogares y Propósitos Múltiples, mayo 2012. 
En cuanto a la distribución relativa de la PEA por rama de actividad y sexo, los datos muestran la preferencia en el sector económico tradicional de cada sexo. Los hombres prefieren insertarse en las ramas de: Agricultura, Caza y Pesca" "Explotación de minas y canteras", "Construcción” y "Electricidad, gas y agua con los respectivos porcentajes $(86.8 \% ; 100 \%, 100 \%$ y 100\%). En cambio las mujeres permanecen insertas en las ramas de "Industria Manufacturera", "Comercio por Mayor/Menor, Hoteles/Restaurantes" y "Servicios Comunales, Sociales y Personales", (67.5\%, 61\% y 49.5\%) respectivamente. Es interesante encontrar mujeres que en estas edades declararon haber buscado empleo por primera vez.

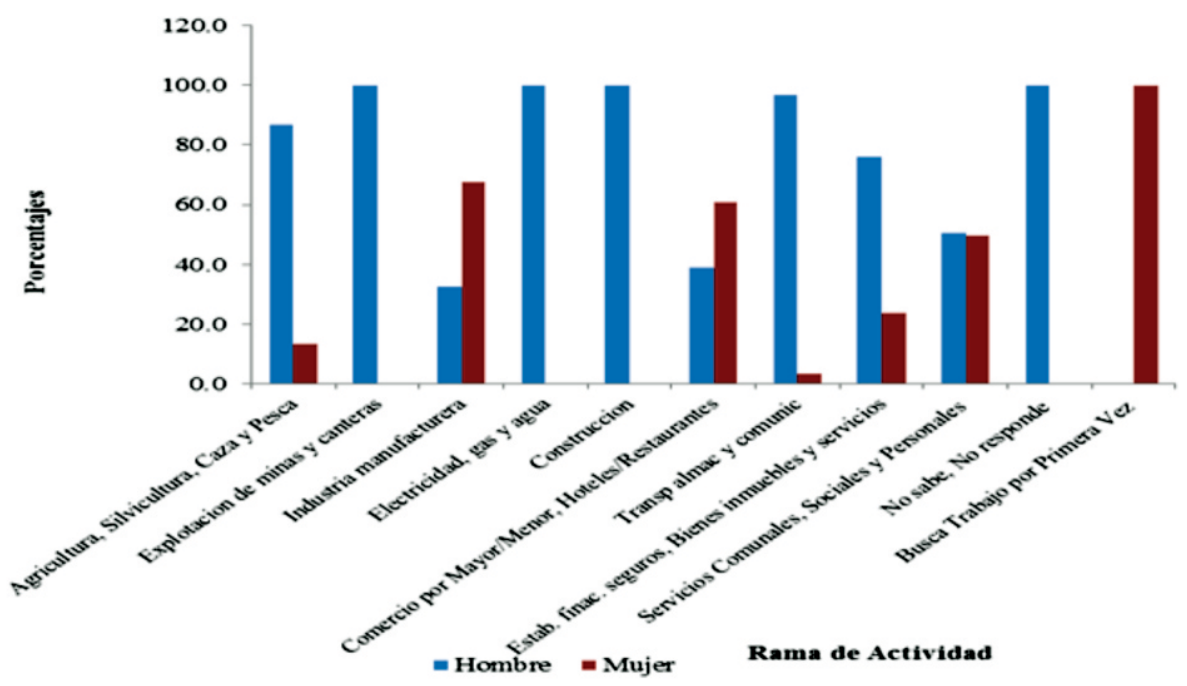

Figura No. 13

PEA adultos Mayores por Rama de Actividad según sexo, 2012

Fuente: INE. Encuesta Permanente de Hogares y Propósitos Múltiples, mayo 2012.

\subsection{Nivel de Empleo}

En la figura siguiente, se presenta los datos del nivel de empleo, donde más del $60 \%$ de los hombres mayores no tienen problemas de empleo en cambio en las mujeres es el $43 \%$. Además se exhibe como los hombres tienen problemas de subempleo Invisible (se refiere a las personas que trabajan 36 horas semanales pero ganan ingresos menores del salario ingresos menores al salario mínimo) eso explica porque los hombres permanecen más tiempo en el mercado laboral. Esta situación de empleo provoca que las personas en edad avanzada estén en situación de vulnerabilidad pues muchas veces el trabajo que ejecutan lo hacen en 
Vol. 4

E\&A

IIES condiciones precarias. En cuanto al subempleo invisible, es mayor en las mujeres, pues ellas prefieren estar empleadas aunque el ingreso a percibir sea menor y la jornada de trabajo extensa, lo que se asume que la mayoría de ellas esta empleada como empleada doméstica o en el mercado informal.

Esta diferenciación por género, se manifiesta porque un gran número de mujeres están insertas como empleadas domésticas, sin embargo los hombres la mayoría se encuentra inserto en la agricultura. (Figura No.14).

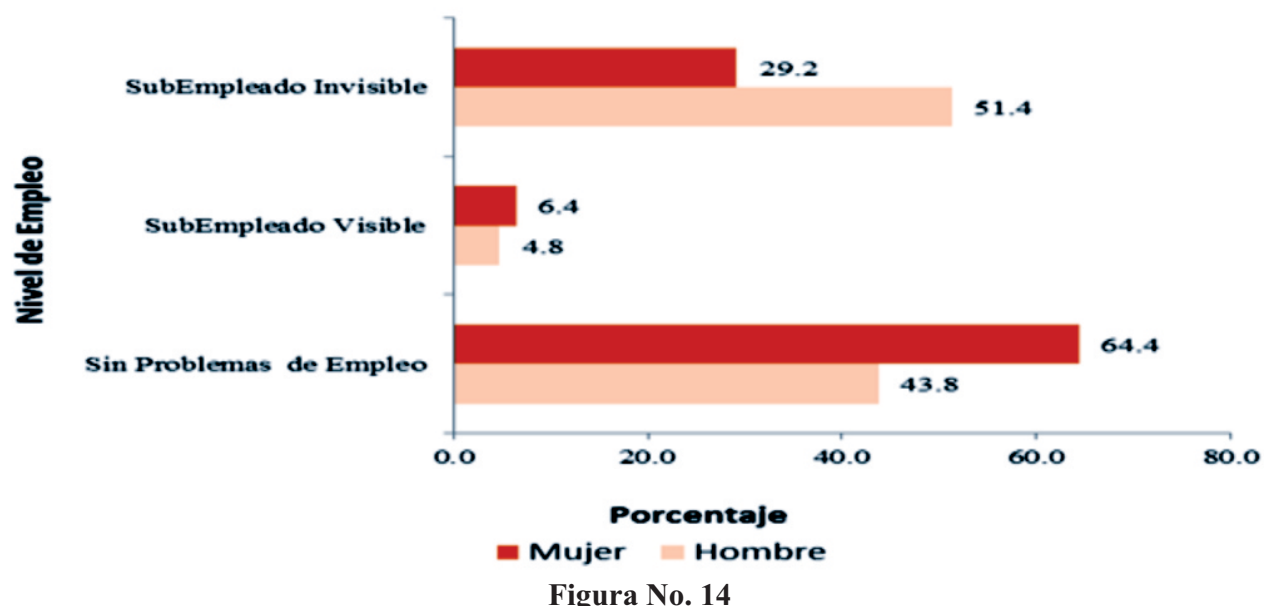

PEA adultos Mayores por Nivel de Empleo según sexo, 2012

Fuente: INE. Encuesta Permanente de Hogares y Propósitos Múltiples, mayo 2012.

\subsection{Horas Trabajadas}

La literatura afirma, que en los países desarrollados las personas que están cercanas al retiro del mercado laboral, realizan esa transición con la facilidad de acceder a un cambio de jornada completas de trabajo de tiempo a jornadas a medio tiempo, pero en los países en desarrollo esa posibilidad no se da fácilmente, por tanto los adultos mayores optan a dejar definitivamente el empleo o la participación en el tiempo normal. A finales de los años ochenta y principios de los noventa se observa un incremento en la importancia del trabajo de medio tiempo para los adultos mayores de 55 años (CISS, 2005).

La figura No. 15, muestra el número de horas que los adultos mayores trabajan a la semana, donde se confirma lo manifestado por la teoría y expresado anteriormente. En Honduras los adultos mayores recurren a trabajar la jornada completa porque no tienen opción de trabajar jornadas menores. Los datos 
muestran que más del 40\% trabajan más de 40 horas semanales donde el 34.5 esta representados por los hombres y el $9.3 \%$ a las mujeres, esto sin duda está relacionado con la participación que tienen las mujeres adultas mayores al mercado laboral. Seguidamente más del 30\% trabajan más de 30 horas a la semana y al igual que en el anterior los hombres lo hacen en mayores proporciones que las mujeres $(23.0 \%$ y $9.3 \%)$ respectivamente.

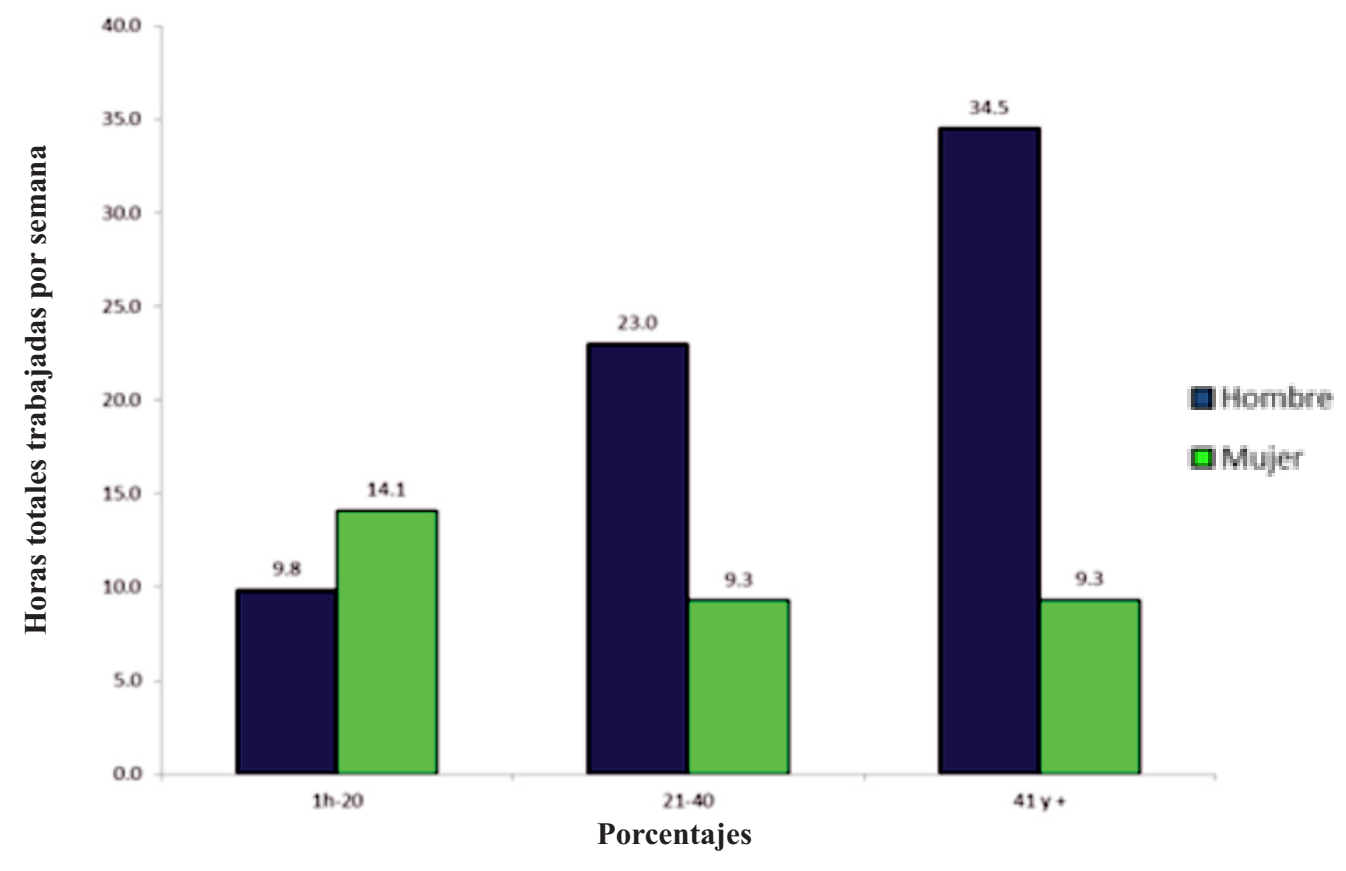

Figura No.15

Honduras: Horas Totales Trabajadas a la Semana por Grupos de Edad, 2012

Fuente: Elaboración propia en base a los datos la EPHPM, mayo 2012

\section{CONCLUSIONES}

1. En Honduras, la cobertura en seguridad social es baja, lo que conlleva a que los adultos mayores tengan que buscar alternativas para tener un ingreso en su vejes. A consecuencia de ello, el 60\% de los adultos mayores que tienen edades menores de 70 años permanecen activos.

2. Existe una alta proporción de los adultos mayores que vive en el área rural, de permanecer insertos en el mercado laboral. El 56.8\% de los adultos mayores que vive en el área rural se mantiene vigente en el mercado laboral 
Vol. 4

E\&A

IIES

80

del área. Aseverando que hay una mayor permanencia de los adultos mayores en el mercado laboral en la zona rural que en la urbana.

3. El análisis realizado nos permitió conocer datos interesantes de los adultos mayores sobre todo en base al empleo donde a pesar que están en edad de retiro siguen aportando a la economía del país, muchos continúan trabajando jornadas de tiempo completo (de forma generalizada por cuenta propia).

4. En cuanto a la distribución de la PEA en las diferentes ocupaciones y ramas de actividad económica, se observa una marcada división por sexo en el trabajo. Tanto los hombres como las mujeres están insertos en actividades propias de su género, aunque la mujer ha ganado espacio en la agricultura el hombre dominando ese campo.

5. Hay una clara inequidad en el empleo de los adultos mayores, pues mientras los hombres presentan tasas de subempleo visible mayores, las mujeres las presentan en el nivel de subempleo invisible.

6. La mayoría de adultos mayores trabaja jornadas completas, especialmente en los dos primeros grupos de edad.

\section{BIBLIOGRAFÍA}

Aranibar, P., 2001. Acercamiento conceptual a la situación del adulto mayor en América Latina. Santiago de Chile, 70p.

Bertranou, F. M., 2006. Coordinador. Envejecimiento, empleo y protección social en América Latina. Santiago de Chile, Oficina Internacional del Trabajo.

Centro Latinoamericano de Demografía, CELADE, 2011. América Latina y el Caribe. Observatorio demográfico $N^{\circ} 12$ Envejecimiento poblacional.

Centro Latinoamericano de Demografía, CELADE, 2012. Estimaciones y proyecciones de Población a largo plazo 1950-2050.

CEPAL, 2003 Conferencia Regional Intergubernamental sobre Envejecimiento: hacia una estrategia regional de implementación para América Latina y el Caribe del Plan de Acción Internacional de Madrid sobre el Envejecimiento. Santiago de Chile. 
CEPAL, 2004. Población, Envejecimiento y Desarrollo. LC/G.2235 (SES.30/16), Santiago de Chile.

CEPAL, 2009. El envejecimiento y las personas de edad: Indicadores sociodemográficos para América Latina y el Caribe.

Chenais, J. C., 1990. El Proceso de Envejecimiento de la Poblacion. Comisión Económica para América Latina y El Caribe, 145 p. (CELADE, Serie E, No $35)$.

CISS, 2005. Mercado Laboral y Seguridad Social en una Sociedad que Envejece: un Resumen para México.

Flores Fonseca, M., 2007. La transición demográfica en Honduras. Tegucigalpa, FNUAP, 61p.

Frómeta Sánchez, E. y Estrada, R, 1997. El envejecimiento de la Población y sus perspectivas. MEDISAN: 1(1): 30-35.

Guzmán, J.M., 2002. El Envejecimiento y desarrollo en América Latina y el Caribe.

Gruber, J. y Wise, D., 2004. Sistema de Seguridad Social y Jubilación en el Mundo. Traducción de Pedro Arévalo. National Bureau of Econo Research. Cuadernos Económicos de ICE no 65.

Haupt y Kane, 2003. Guía rápida de población. Population Reference Bureau. 4ed. 70p.

INDEC, 1999. Situación Demográfica de la Provincia de Tucumán. Ministerio de Economía y Obras de Servicios Públicos. Secretaria de Programas Económicas y Regionales. Instituto Nacional de Estadísticas y Censos, 86p.

INE, 2012. XLIII Encuesta Permanente de Hogares Y Propósitos Múltiples. Tegucigalpa, Honduras.

Popolo del F., 2001. Características Sociodemográficas y Socioeconómicas de las Personas de Edad en America Latina. Santiago de Chile. CELADE, Pg. 56. 
Vol. 4 $\mathrm{N}^{\circ} 1$

2013

E\&A IIES

82

Trejo Teruel, E.G., 2005. El Proceso de Envejecimiento Demográfico en Honduras, reflexión a partir de la Población Adulta Mayor en los Municipios del Corredor Centro Sur del Pais, Revista Centro Americana de Ciencias Sociales, No. 2, Volumen II.

Zelaya Ochoa, M I., 2011. El envejecimiento en Honduras. Informe presentado en el Día del Adulto mayor en Honduras. Tegucigalpa. 